\title{
TREM-2 promotes Th1 responses by interacting with the CD3 $\zeta$-ZAP70 complex following Mycobacterium tuberculosis infection
}

\author{
Yongjian Wu, ${ }^{1,2,3,4}$ Minhao Wu, ${ }^{1}$ Siqi Ming, ${ }^{1,2,5}$ Xiaoxia Zhan, ${ }^{1}$ Shengfeng Hu, ${ }^{1}$ Xingyu Li, ${ }^{1,2}$ Huan Yin, ${ }^{1,2}$ Can Cao, ${ }^{1,2}$ Jiao Liu, ${ }^{1,2}$ \\ Jinai Li, ${ }^{1,2}$ Zhilong Wu, ${ }^{6}$ Jie Zhou, ${ }^{6}$ Lei Liu, ${ }^{5}$ Sitang Gong, ${ }^{4}$ Duanman He, ${ }^{7}$ and Xi Huang ${ }^{1,2,3,4,5}$ \\ ${ }^{1}$ Center for Infection and Immunity, The Fifth Affiliated Hospital of Sun Yat-sen University, Zhuhai, Guangdong Province, China. ${ }^{2}$ Guangdong Provincial Engineering Research Center of Molecular \\ Imaging, Guangdong Provincial Key Laboratory of Biomedical Imaging, and Department of Interventional Medicine, The Fifth Affiliated Hospital, Sun Yat-sen University, Zhuhai, China. ${ }^{3}$ Southern \\ Marine Science and Engineering Guangdong Laboratory, Zhuhai, Guangdong Province, China. ${ }^{4}$ Department of Gastroenterology, Guangzhou Women and Children's Medical Center, Guangzhou Institute \\ of Pediatrics, Guangzhou Medical University, Guangzhou, Guangdong Province, China. ${ }^{5}$ National Clinical Research Center for Infectious Disease, Shenzhen Third People's Hospital, The Second Affiliated \\ Hospital of the Southern University of Science and Technology, Shenzhen, Guangdong Province, China. ${ }^{6}$ The Fourth People's Hospital of Foshan, Foshan, China. 'Shantou No. 3 People's Hospital, \\ Shantou, Guangdong Province, China.
}

\begin{abstract}
Triggering receptor expressed on myeloid cells 2 (TREM-2) is a modulator of pattern recognition receptors on innate immune cells that regulates the inflammatory response. However, the role of TREM- 2 in in vivo models of infection and inflammation remains controversial. Here, we demonstrated that TREM-2 expression on CD4+ T cells was induced by Mycobacterium tuberculosis infection in both humans and mice and positively associated with $\mathrm{T}$ cell activation and an effector memory phenotype. Activation of TREM- 2 in CD4 ${ }^{+} \mathrm{T}$ cells was dependent on interaction with the putative TREM-2 ligand expressed on DCs. Unlike the observation in myeloid cells that TREM-2 signals through DAP12, in CD4 ${ }^{+}$T cells, TREM-2 interacted with the CD3 $\zeta$-ZAP70 complex as well as with the IFN- $\gamma$ receptor, leading to STAT1/-4 activation and T-bet transcription. In addition, an infection model using reconstituted Rag2 ${ }^{-1-}$ mice (with TREM-2-KO vs. WT cells or TREM-2+ vs. TREM-2-CD4+ T cells) or CD4 ${ }^{+}$T cell-specific TREM-2 conditional KO mice demonstrated that TREM-2 promoted a Th1-mediated host defense against M. tuberculosis infection. Taken together, these findings reveal a critical role of TREM-2 in evoking proinflammatory Th1 responses that may provide potential therapeutic targets for infectious and inflammatory diseases.
\end{abstract}

\section{Introduction}

Pattern recognition receptors (PRRs) usually function to modulate immune responses and participate in host defense against $\mathrm{Myco}$ bacterium tuberculosis. Recent evidence has demonstrated that, upon infection or inflammation, certain PRRs such as TLRs are also expressed on $\mathrm{T}$ lymphocytes, providing costimulatory signals to induce $\mathrm{T}$ cell activation and differentiation (1). Several regulators have been reported to modulate TLR signaling pathways, such as triggering receptors expressed on myeloid cells (TREMs). TREMs belong to a family of innate receptors that are broadly expressed on macrophages, monocytes, and DCs $(2,3)$. The most well-characterized members of the TREM family are TREM-1 and TREM-2, which signal through the same adaptor molecule, DAP12, but have distinct functions in inflammation modulation (4-6). In myeloid cells, TREM-1 amplifies TLR signaling and host inflammation $(4,7)$, whereas TREM-2 inhibits the secretion of proinflammatory cytokines induced by bacterial or fungal infection $(5,8)$. TREM-2 has powerful functions in neurodegenerative

Conflict of interest: The authors have declared that no conflict of interest exists. Copyright: () 2021, American Society for Clinical Investigation.

Submitted: February 19, 2020; Accepted: July 20, 2021; Published: September 1, 2021.

Reference information: J Clin Invest. 2021;131(17):e137407.

https://doi.org/10.1172/JCl137407. diseases and plays critical roles in the modulation of inflammation as well as myeloid cell activation and survival $(9,10)$. TREM-2 deficiency leads to severe disease characterized by bone cysts and demyelination of the central nervous system (CNS) (11). Genetic variants in TREM-2 increase the risk for Alzheimer's disease and frontotemporal dementia (12-14). Various molecules have been reported to bind to TREM-2, including certain cell-surface molecules (5), bacteria, or heat shock proteins (15), as well as lipids exposed during axonal injury (16) and nucleic acid released from dying cells (17). Nevertheless, to date, the endogenous ligands of TREM-2 are still unclear. Recently, studies reported that apolipoprotein E (18) and galectin 3 (19) may function as novel TREM-2 ligands to modulate the development of Alzheimer's disease.

Although substantial evidence identifies the antiinflammatory property of TREM-2 in innate immune cells (8), in vivo studies have shown controversial effects of TREM- 2 on the modulation of infectious and inflammatory diseases. On the one hand, TREM-2 fine-tunes inflammatory responses in a murine model of sepsis induced by Gram-negative bacteria (20). Mice lacking TREM-2 exhibit aggravated liver damage and inflammation in a chemical reagent-induced liver injury model (6). On the other hand, TREM-2 deficiency attenuates the inflammatory response and restricts organ damage and mortality induced by Burkholderia pseudomallei infection (21). KO of TREM-2 also inhibits neuroinflammation 
and protects against neurodegeneration in a mouse model of tauopathy (22). These controversial reports highlight the necessity to fully explore the functions of TREM-2 in distinct diseases and other immune cell subsets such as lymphocytes, as opposed to just the myeloid lineage.

Our previous study demonstrated that TREM-1 is highly expressed on $\mathrm{V} \delta 2 \mathrm{~T}$ cells from patients with active pulmonary tuberculosis (TB) and promotes the Ag-presenting capability of V $82 \mathrm{~T}$ cells (23). It is reported that the expression of TREM-like transcript 2 (TLT2) is detected on B lymphoid lineage cells and upregulated in response to inflammatory stimuli (24). TLT2 is also constitutively expressed on $\mathrm{CD}^{+} \mathrm{T}$ cells and enhances IL- 2 and IFN- $\gamma$ production (25). Furthermore, TREM-2 expression in $\mathrm{CD}^{+}$and $\mathrm{CD}^{+} \mathrm{T}$ cells has been reported in patients with TB (26), however, the function of TREM-2 in TB remains unknown. Together, these observations indicate the potential roles of TREM family members in lymphocytes.

$\mathrm{CD}^{+} \mathrm{T}$ cells are crucial for directing appropriate immune responses in host defense and inflammatory pathogenesis (27). In the inflammatory and infectious milieu, the most abundant effector $\mathrm{CD}^{+}{ }^{+}$Th subset is Th1, which is characterized by the activation of T-bet and production of Th1 cytokines including IFN- $\gamma$, TNF, and IL-2 (28). These Th1 cytokines enhance cell-mediated immunity to promote the elimination of intracellular pathogens (e.g., M. tuberculosis [ref. 29], Mycobacterium leprae [ref. 30], and Listeria monocytogenes [ref. 31]). For example, IFN- $\gamma$ - or TNFdeficient mice display exacerbated pulmonary pathology with a high acid-fast bacilli burden after M. tuberculosis infection $(32,33)$, indicating the beneficial role of the Th1 response in anti-TB immunity. The Th1 response is not only required in the host defense against various bacterial and viral infections, but also evokes phagocyte-dependent inflammation (34). The inflammatory response is a double-edged sword. Early initiation of host inflammation is beneficial for bacterial clearance, however, if uncontrolled, consistent inflammation may result in immunopathological damage (35). Therefore, Th1 dominance is often associated with autoimmune disorders (e.g., inflammatory bowel diseases, type 1 diabetes, multiple sclerosis, rheumatoid arthritis), Alzheimer's disease, and some recurrent abortions (36-38).

In this study, we investigated the role of TREMs on $\mathrm{T}$ cell responses during $M$. tuberculosis infection. TREM-2 expression was upregulated in $\mathrm{CD} 4^{+} \mathrm{T}$ cells from patients with $\mathrm{TB}$ and $M$. tuberculosis-infected mice and closely related to $\mathrm{T}$ cell activation and an effector memory phenotype. In vitro studies indicated that TREM-2 interacted with the CD3ל-ZAP70 complex via its transmembrane domain (especially the K173 site), rather than with the adaptor molecule DAP12 in myeloid cells, and therefore promoted STAT1/-4 activation and proinflammatory Th1 differentiation. Furthermore, in vivo studies demonstrated that TREM-2 enhanced the CD4 ${ }^{+} \mathrm{T}$ cell-mediated host antimycobacterial defense. Overall, these results demonstrate a critical role of TREM-2 in evoking proinflammatory Th1 responses, which may provide useful information for the development of a therapeutic target for TB and other infectious and inflammatory diseases.

\section{Results}

TREM-2 expression on $C D 4^{+} T$ cells is increased during mycobacterial infection. To explore the expression profile of TREMs in T cells and monocytes during $M$. tuberculosis infection, $\mathrm{CD}^{+}{ }^{+} \mathrm{T}$ cells, $\mathrm{CD}^{+}$ $\mathrm{T}$ cells, and $\mathrm{CD}_{11 \mathrm{~b}^{+}}$monocytes were sorted from PBMCs from patients with active TB or healthy control donors (HCs) (Supplemental Table 1; supplemental material available online with this article; https://doi.org/10.1172/JCI137407DS1). mRNA levels of TREM-1, TREM-2, and TLT2 were analyzed by quantitative realtime PCR. In HCs, TREM-1 expression was hardly detected in any of the indicated cell types, whereas TREM-2 was constitutively expressed in $\mathrm{CD}_{11} \mathrm{~b}^{+}$monocytes rather than in $\mathrm{CD} 4^{+}$and $\mathrm{CD} 8^{+} \mathrm{T}$ cells (Figure 1A and Supplemental Figure 1A). In patients with TB, we found that TREM-1 was weakly expressed on T cells, whereas TREM-2 was highly expressed on T cells and monocytes (Figure 1A and Supplemental Figure 1A). TLT2 was detected in all the cell types (Supplemental Figure 1B), which is consistent with other previous studies $(24,25)$.

Flow cytometry further detected TREM-2 expression on the surface of the indicated PBMC subsets from HCs and from patients with TB. Although TREM-2 $2^{+}$staining was mainly found in monocytes from HCs, TREM-2 expression levels were increased in T cells from patients with TB (Figure 1B). Additionally, immunofluorescence microscopy also detected increased TREM-2 expression in peripheral $\mathrm{CD} 4^{+} \mathrm{T}$ cells but not $\mathrm{CD} 14^{+}$monocytes from patients with TB compared with those from HCs (Figure 1C and Supplemental Figure 2). To further explore the clinical relevance of TREM-2 in TB, we assessed TREM-2 expression in CD $4^{+}$ T cells from HCs $(n=81)$ and from patients with active TB $(n=$ $116)$, latent TB $(n=30)$, cured TB $(n=43)$, or chronic obstructive pulmonary disease (COPD) $(n=22)$ (Supplemental Table 1$)$. The percentage of peripheral TREM- ${ }^{+} \mathrm{CD} 4^{+} \mathrm{T}$ cells was increased in patients with active TB $(26.25 \% \pm 1.16 \%)$ or latent TB $(15.33 \% \pm$ $1.14 \%)$, but not in those with cured TB $(9.62 \% \pm 0.95 \%)$ or COPD $(8.42 \% \pm 1.13 \%)$ when compared with the basal level in HCs $(6.14 \% \pm 0.43 \%)$ (Figure 1, D and E).

To evaluate the dynamics of TREM-2 expression in $\mathrm{CD}^{+} \mathrm{T}$ cells during mycobacterial infection, we established a murine model by i.p. injection of Mycobacterium bovis bacille Calmette-Guérin (BCG) or the M. tuberculosis strain H37Rv. First, we analyzed the proportion of TREM-2 ${ }^{+} \mathrm{CD} 4^{+} \mathrm{T}$ cells in peripheral blood, draining lymph nodes, spleens, and lungs 28 days post infection (p.i.). We found that the basal levels of TREM- $2^{+} \mathrm{CD} 4^{+} \mathrm{T}$ cells in PBS-treated mice were very low in all the indicated tissues. Nonetheless, after BCG or $\mathrm{H} 37 \mathrm{Rv}$ infection, TREM- $2^{+} \mathrm{CD} 4^{+} \mathrm{T}$ cells percentages were increased in all the indicated tissues (Figure 1, F and G). In addition, we assessed the frequency of splenic TREM $-2^{+} \mathrm{CD} 4^{+} \mathrm{T}$ cells by flow cytometry at different p.i. time points. The percentage of TREM $-2^{+} \mathrm{CD} 4^{+} \mathrm{T}$ cells gradually increased in the early p.i. period, peaked on day 28 p.i., and decreased slowly thereafter (Figure $1 \mathrm{H}$ ). Furthermore, TREM-2 expressions in peripheral CD8 ${ }^{+} \mathrm{T}$ cells from HCs $(n=81)$ and from patients with active TB $(n=116)$, latent TB $(n=30)$, cured TB $(n=43)$, or COPD $(n=22)$ were determined by flow cytometry (Supplemental Table 1 ). The percentages of TREM$2^{+} \mathrm{CD}^{+} \mathrm{T}$ cells in patients with active $\mathrm{TB}(12.57 \% \pm 0.77 \%)$ or latent TB $(7.14 \% \pm 0.67 \%)$ were higher than those in other groups, including HCs $(3.43 \% \pm 0.29 \%)$, patients with cured TB $(3.92 \% \pm$ $0.34 \%)$, and patients with COPD $(4.55 \% \pm 0.61 \%)$ (Supplemental Figure $3 \mathrm{~A}$ ). Taken together, these results indicated a potential role of TREM-2 in T cell-mediated immunity against TB. 

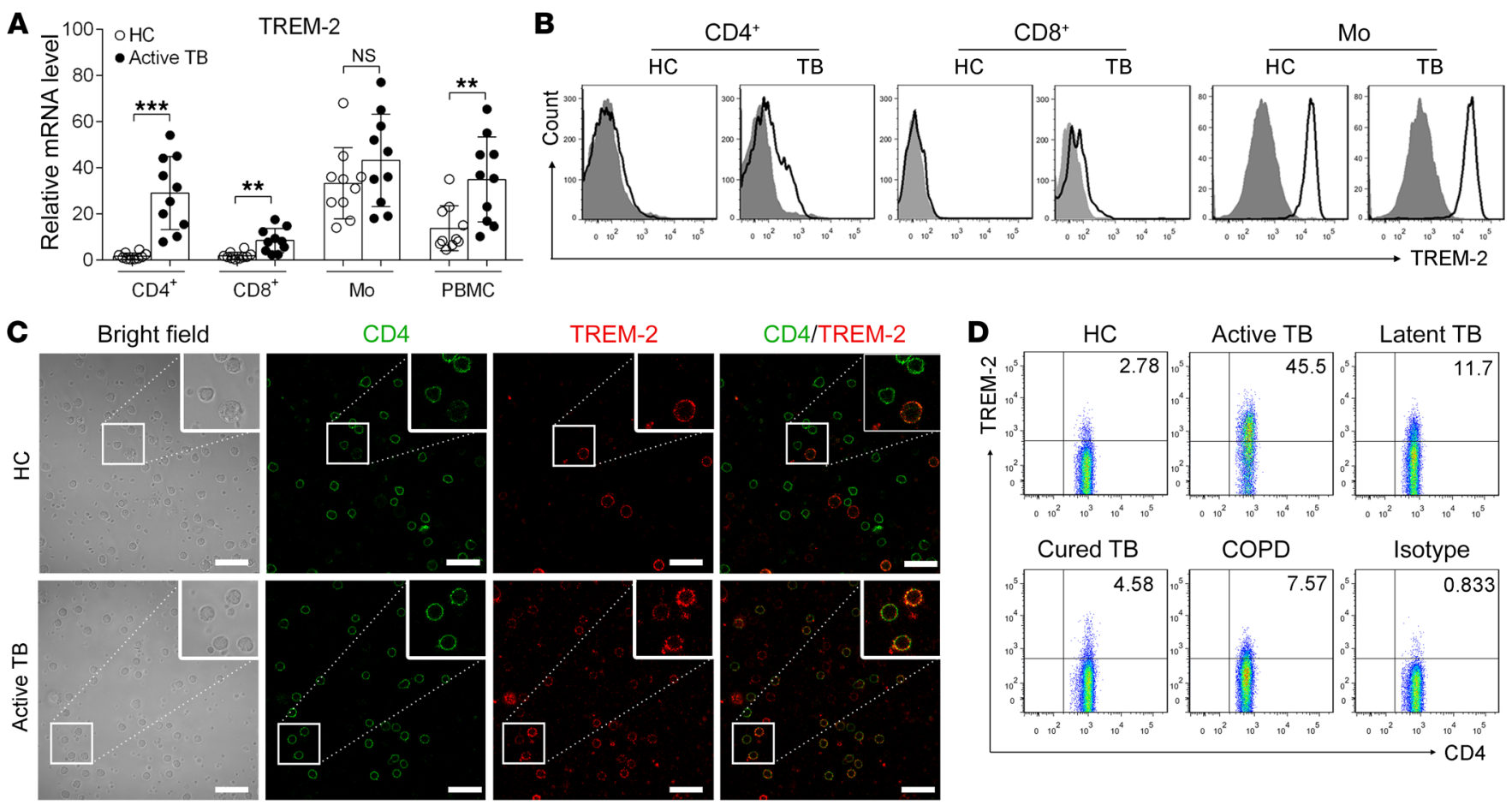

$\mathbf{E}$

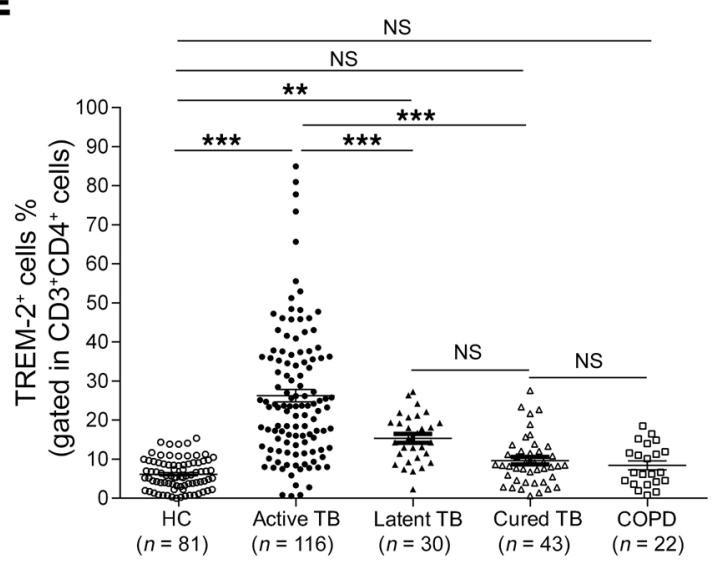

$\mathbf{F}$

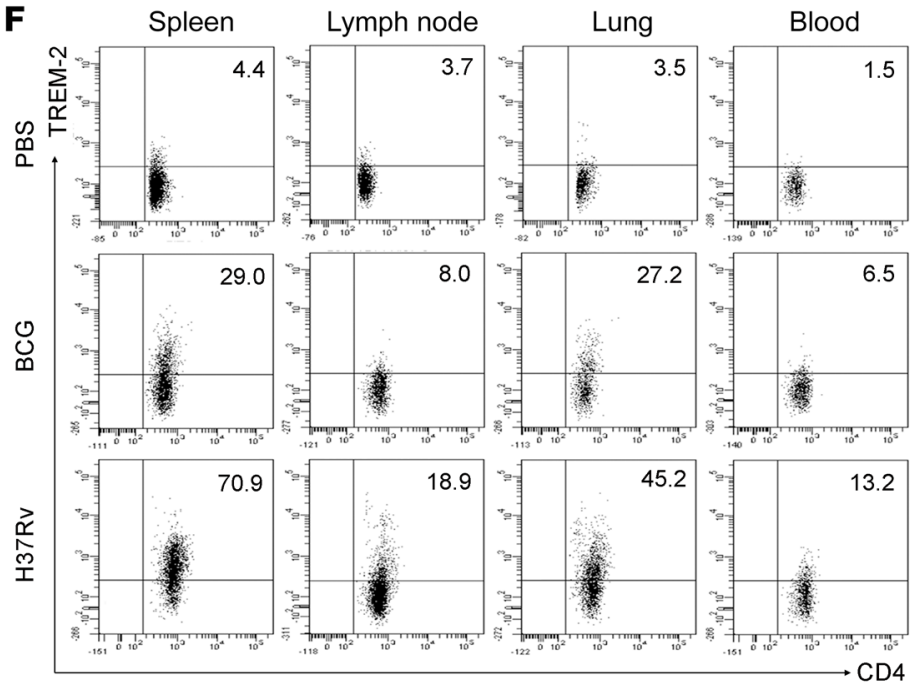

G

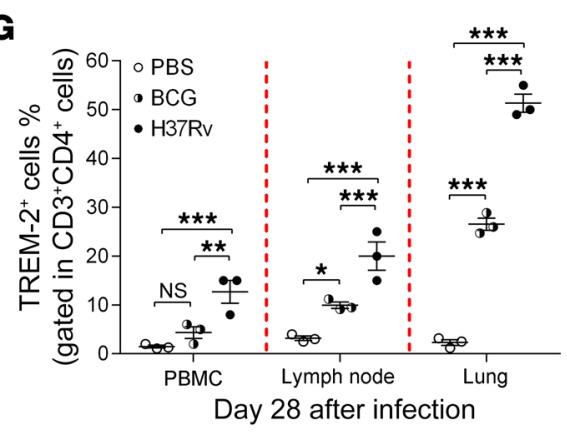

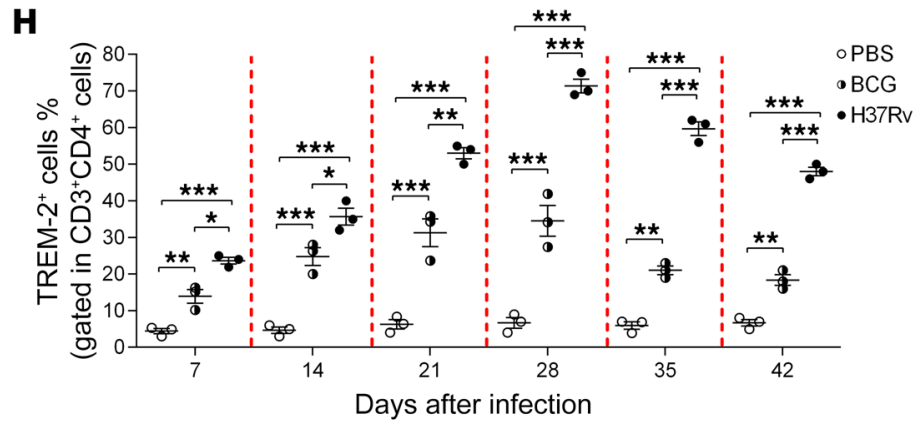


Figure 1. M. tuberculosis infection induces TREM-2 expression in $\mathrm{CD4}^{+} \mathrm{T}$ cells. (A and B) Expression levels of TREM- 2 in CD4 ${ }^{+} T$ cells, $C D 8^{+} T$ cells, CD14 ${ }^{+}$monocytes (Mo), or PBMCs from HCs $(n=10)$ or patients with active TB $(n=10)$ were analyzed by quantitative real-time PCR $(\mathbf{A})$ and flow cytometry (B). White and shaded histograms, respectively, show staining with TREM-2 Abs and an isotype control. (C) PBMCs from HCs or patients with active TB were double-stained with anti-CD4 (green) and anti-TREM-2 (red) Abs and then observed by fluorescence microscopy. Scale bars: 50 $\mu \mathrm{m}$; original magnification, $\times 40$ (enlarged insets). (D and E) Flow cytometric analysis of TREM-2 expression in CD4 ${ }^{+}$T cells from HCs $(n=81)$ and patients with active TB $(n=116)$, latent TB $(n=30)$, cured TB $(n=43)$, or COPD $(n=22)$. (F-H) C57BL/6 mice were injected i.p. with $1 \times 10^{6} \mathrm{CFU}$ M. bovis BCC $(n=3)$ or H37Rv $(n=3)$. The proportion of TREM-2+CD4+ $T$ cells was assessed by flow cytometry in the indicated organs 28 days p.i. (C), or in spleens at the indicated time points $(\mathbf{H})$. Data represent the mean $\pm \mathrm{SD}$ from at least 3 independent experiments. ${ }^{*} P<0.05$, ${ }^{*} P<0.01$, and ${ }^{* *} P<0.001$, by unpaired Student's $t$ test $(\mathbf{A})$ and 1-way ANOVA $(\mathbf{E}-\mathbf{H})$.

TREM-2 expression is positively correlated with activation and a memory phenotype of $C D 4^{+} T$ cells. Next, we performed flow cytometry to determine the expression of $\mathrm{T}$ cell activation markers including CD44, CD69, and CD25, as well as the chemokine receptor CXCR3 on TREM-2 $2^{+} \mathrm{CD} 4^{+}$versus TREM-2-CD $4^{+} \mathrm{T}$ cells (Figure 2, A-D). In patients with active TB $(n=30)$, TREM-2 ${ }^{+}$ $\mathrm{CD}^{+} \mathrm{T}$ cells had higher levels of all the indicated activation markers compared with levels in TREM-2 ${ }^{-} \mathrm{CD} 4^{+} \mathrm{T}$ cells (Figure 2, A-D). Since $\mathrm{CD}^{+} \mathrm{T}$ cells differentiate into distinct effector or memory cell subsets after activation, we further analyzed the phenotype of TREM- $2^{+} \mathrm{CD} 4^{+} \mathrm{T}$ cells by double-staining with Abs against CD45RO and CCR7 or CD27, which divide CD4 ${ }^{+} \mathrm{T}$ cells into 4 subsets: naive $\mathrm{T}$ cells $\left(\mathrm{CD} 45 \mathrm{RO}^{-} \mathrm{CCR} 7^{+}\right.$or $\mathrm{CD} 45 \mathrm{RO}$ $\left.\mathrm{CD} 27^{+}\right)$, central memory $\mathrm{T}(\mathrm{Tcm})$ cells $\left(\mathrm{CD} 45 \mathrm{RO}^{+} \mathrm{CCR} 7^{+}\right.$or $\left.\mathrm{CD}^{2} 5 \mathrm{RO}^{+} \mathrm{CD} 27^{+}\right)$, effector memory $\mathrm{T}(\mathrm{Tem})$ cells $\left(\mathrm{CD} 45 \mathrm{RO}^{+}\right.$ $\mathrm{CCR}^{-}$or $\left.\mathrm{CD}^{-1} 5 \mathrm{RO}^{+} \mathrm{CD} 27^{-}\right)$, and terminally differentiated effector $\mathrm{T}$ (Temra) cells (CD45RO-CCR7 ${ }^{-}$or $\left.\mathrm{CD}^{-} 5 \mathrm{RO}^{-} \mathrm{CD} 27^{-}\right)$. As observed in T cells from patients with active TB $(n=40)$ whose $\mathrm{T}$ cells were stained with CD45RO and CCR7, the frequency of $\mathrm{Tcm}$, Tem, and Temra cells was increased, while the frequency of naive $\mathrm{T}$ cells was decreased in TREM- $2^{+} \mathrm{CD} 4^{+} \mathrm{T}$ cells compared with TREM-2 ${ }^{-} \mathrm{CD} 4^{+} \mathrm{T}$ cells (Figure $2 \mathrm{E}$ ). We further confirmed these observations by staining for CD45RO and CD27 in T cells from another cohort of patients with active TB $(n=21)$ (Figure $2 \mathrm{~F}$ ). Meanwhile, we analyzed TREM-2 expression in different CD $4^{+}$ $\mathrm{T}$ cell subsets and found that TREM- 2 expression in naive CD $4^{+}$ $\mathrm{T}$ cells was much lower than that in effector and memory $\mathrm{T}$ cell subsets (Tcm, Tem, and Temra) (Supplemental Figure 4, A and B).

Consistently, in the lungs and spleens from H37Rv-infected C57BL/6 mice, expression levels of the $\mathrm{T}$ cell activation markers CD69 and CD25 were increased in TREM-2+CD4 ${ }^{+}$versus TREM-2 $\mathrm{CD}^{+} \mathrm{T}$ cells (Supplemental Figure 5, A and B). Moreover, increased proportions of Tem cells $\left(\mathrm{CD} 44^{+} \mathrm{CD} 62 \mathrm{~L}^{-}\right)$and decreased proportions of naive $\mathrm{T}$ cells $\left(\mathrm{CD} 44^{-} \mathrm{CD} 62 \mathrm{~L}^{+}\right)$were detected in TREM-2+ compared with TREM-2 ${ }^{-} \mathrm{CD} 4^{+} \mathrm{T}$ cells (Supplemental Figure 5C). Moreover, sorted WT and TREM-2/- CD $4^{+}$ $\mathrm{T}$ cells were respectively transferred into $\mathrm{Rag} 2^{-/-}$mice, followed by infection with $\mathrm{H} 37 \mathrm{Rv}$. In the lungs and spleens of $\mathrm{Rag}^{-/-}$recipient mice, we observed that the frequencies of $\mathrm{CD} 69^{+}$and $\mathrm{CD} 25^{+}$cells were significantly reduced in TREM-2-/- compared with WT CD $4^{+}$
T cells (Supplemental Figure 6, A and B). In addition, deficiency of TREM- 2 in CD4 ${ }^{+} \mathrm{T}$ cells reduced the proportion of Tem and Tcm cells, but increased the frequency of naive T cells (Supplemental Figure 6C). Together these data indicated that TREM-2 was positively correlated with the activation and effector memory differentiation of $\mathrm{CD} 4^{+} \mathrm{T}$ cells.

TREM-2 signal induces $C D 4^{+} T$ cell activation via $T$ cell-antigen-presenting cell interaction. TREM-2 ligand (TREM-2L) expression on macrophages was previously observed by staining with TREM-2-Fc fusion protein (5). We thus used mouse TREM-2-Fc fusion protein to measure the expression of the putative ligand for TREM-2 in macrophages and DCs. $\mathrm{F} 4 / 80^{+}$macrophages and CD11 $\mathrm{c}^{+}$DCs had higher expression levels of mouse TREM-2L in the spleens of H37Rv-infected mice (Figure 3A). Expression of TREM-2L was barely detected on $\mathrm{CD} 9^{+} \mathrm{B}$ and $\mathrm{CD}^{+} \mathrm{T}$ cells (Figure $3 \mathrm{~A})$. Moreover, the frequency of TREM- $2 \mathrm{~L}^{+}$macrophages and DCs was increased in the spleens of H37Rv-infected mice compared with uninfected controls (Supplemental Figure 7, A and B). In addition, expression of human TREM-2L, as determined by human TREM-2-Fc fusion protein expression, was increased on monocyte-derived DCs infected with H37Rv (Figure 3B) or heatkilled H37Rv (Figure 3C).

Next, we analyzed the activity of TREM- $2^{+} \mathrm{CD} 4^{+} \mathrm{T}$ cells regulated by TREM-2L/TREM-2 signaling in the coculture system. First, splenic WT and TREM-2/-- naive CD4 ${ }^{+} \mathrm{T}$ cells from WT or TREM-2 ${ }^{-/}$mice were sorted and then stained with CFSE, followed by in vitro stimulation with heat-killed, H37Rv-primed DCs, which expressed high levels of TREM-2L (Figure 3C). After 3 days of stimulation, we observed that $\mathrm{WT} \mathrm{CD} 4^{+} \mathrm{T}$ cells proliferated more quickly than did TREM-2-/ $\mathrm{CD} 4^{+} \mathrm{T}$ cells (Figure 3, D and $\mathrm{E}$ ). In addition, WT CD4 ${ }^{+} \mathrm{T}$ cells produced more IFN- $\gamma$ than did TREM-2-1- CD4 ${ }^{+} \mathrm{T}$ cells after 3 days of coculturing with heatkilled, H37Rv-primed DCs (Figure 3F). Moreover, treatment with mouse TREM-2-Fc fusion protein reduced cell proliferation and production of IFN- $\gamma$ in WT CD $4^{+} \mathrm{T}$ cells, but had no significant effect on TREM-2-/- CD4 ${ }^{+} \mathrm{T}$ cells (Figure $3, \mathrm{D}-\mathrm{F}$ ). To confirm these results, human TREM-2+ and TREM-2 ${ }^{-} \mathrm{CD} 4^{+} \mathrm{T}$ cells from PBMCs of HCs were sorted and then stained with CFSE, followed by in vitro stimulation with heat-killed, H37Rv-primed DCs in the presence of human TREM-2-Fc fusion protein or the isotype control. TREM $-2^{+} \mathrm{CD} 4^{+} \mathrm{T}$ cells had greater proliferation and IFN- $\gamma$ production compared with TREM-2-CD4 ${ }^{+} \mathrm{T}$ cells (Figure 3, G-I). Treatment with TREM-2-Fc significantly reduced the proliferation and IFN- $\gamma$ production in TREM- $2^{+} \mathrm{CD} 4^{+} \mathrm{T}$ cells at 3 days after stimulation compared with the isotype control, but did not affect TREM-2- CD4 ${ }^{+}$T cell response (Figure 3, G-I). However, TREM-2 deficiency in DCs did not affect $\mathrm{CD} 4^{+} \mathrm{T}$ cell proliferation (Supplemental Figure 8). Together, these results indicated that TREM-2L/ TREM- 2 signaling induced $\mathrm{CD}^{+} \mathrm{T}$ cell activation via $\mathrm{T}$ cell-antigen-presenting cell ( $\mathrm{T}$ cell-APC) interaction.

TREM-2 facilitates the proliferation and Th1 differentiation of $M$. tuberculosis-specific $C D 4^{+}$T cells. Next, we analyzed the correlation between TREM-2 expression and $\mathrm{CD}^{+}$or $\mathrm{CD} 8^{+} \mathrm{T}$ cell percentages in PBMCs from patients with active TB $(n=116)$ or from HCs $(n=$ 81). The results showed that TREM- 2 expression on $\mathrm{CD}^{+} \mathrm{T}$ cell surfaces was positively correlated with the frequency of peripheral $\mathrm{CD} 4^{+} \mathrm{T}$ cells in patients with active TB $(n=116, r=0.607$, 
A

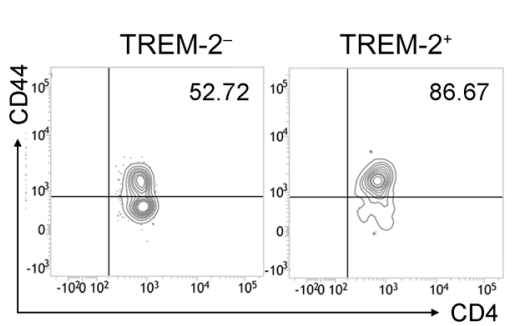

C

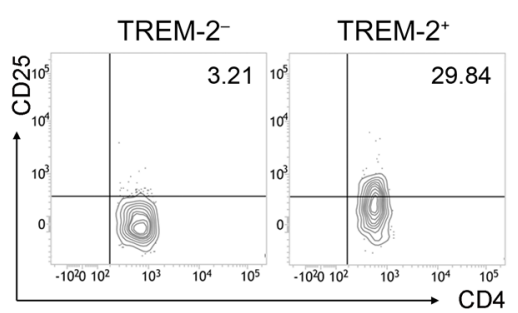

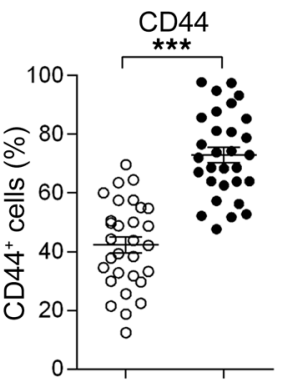

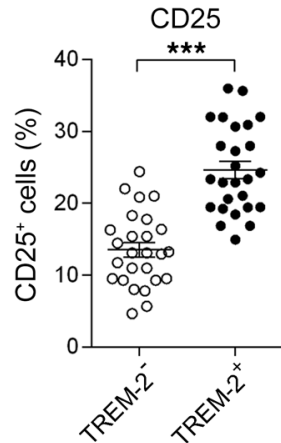

E TREM-2-

TREM-2+
B

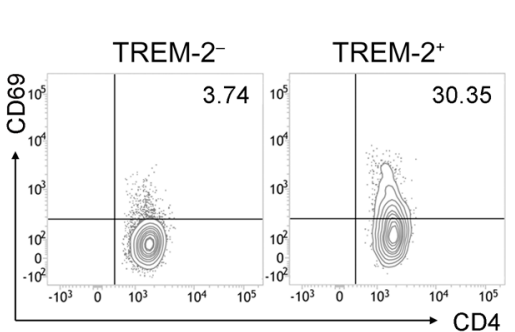

D

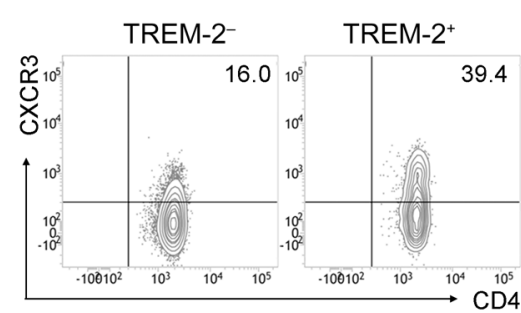

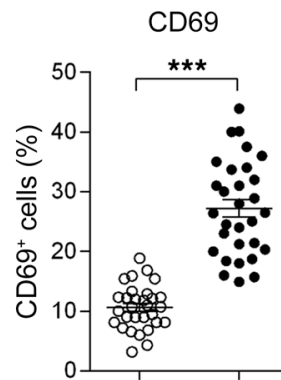

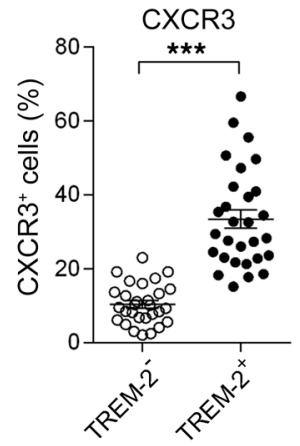

$\mathbf{F}$

TREM-2-

TREM-2+
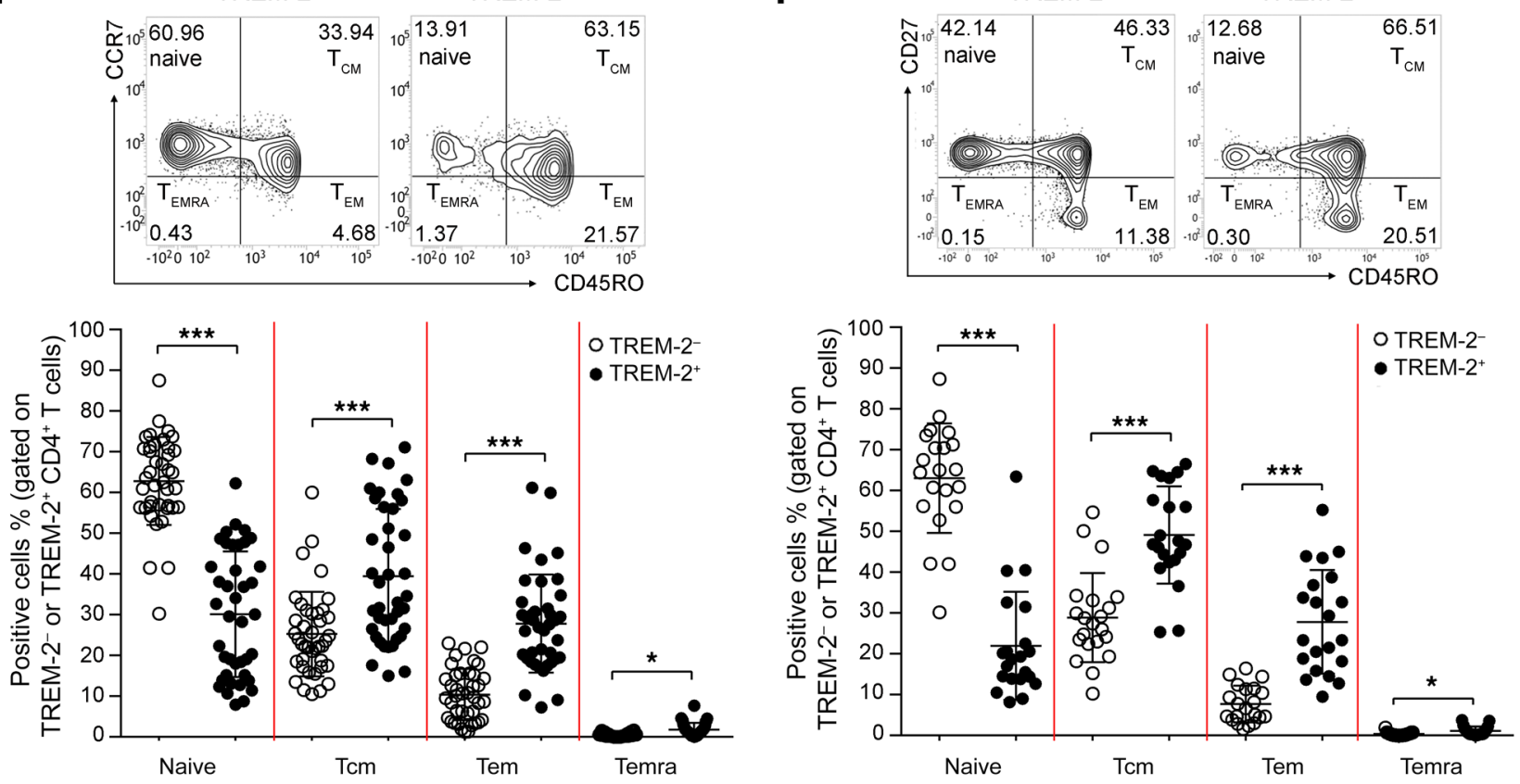

Figure 2. TREM-2+CD4 ${ }^{+} \mathrm{T}$ cells display an activation and effector memory phenotype in patients with active TB. Expression levels of T cell activation markers including CD44 (A), CD69 (B), and CD25 (C) as well as the chemokine receptor CXCR3 (D) were determined by flow cytometry in TREM-2+CD4+ and TREM-2-CD4+ $T$ cells from patients with active TB $(n=30)$. The percentages of positive cells for each indicated marker in TREM-2+CD4+ versus TREM-2CD4 ${ }^{+}$T cells were compared. (E and F) Flow cytometric analysis of CD45RO/CCR7 $(n=40)$ and CD45RO/CD27 $(n=21)$ staining to define the T cell subsets in TREM-2+CD4+ versus TREM-2-CD4+ T cells from patients with active TB. The percentages of naive T cells, Tem cells, Tcm cells, and terminally differentiated effector Temra cells were compared between TREM-2+CD4+ and TREM-2-CD4+ $T$ cells. Data represent the mean \pm SD from at least 3 independent experiments. Unpaired Student's $t$ test was performed in A-F. ${ }^{*} P<0.05$ and ${ }^{* *} P<0.001$.

$P<0.01)$, but not in HCs $(n=81, r=0.109, P>0.05)$ (Figure 4 A). This phenomenon was also observed in peripheral $\mathrm{CD} 8^{+} \mathrm{T}$ cells, but the correlation was much weaker than that in $\mathrm{CD} 4^{+} \mathrm{T}$ cells (Supplemental Figure 3B, $n=116, r=0.269, P<0.01$ ). Therefore, we mainly focused on the role of TREM- 2 on $\mathrm{CD} 4^{+} \mathrm{T}$ cells in the subsequent experiments.
First, TREM- $2^{+}$and TREM-2-CD4 ${ }^{+} \mathrm{T}$ cells from PBMCs from patients with active TB were sorted by flow cytometry, stained with CFSE, and then cocultured with heat-killed, H37Rv-primed DCs. After 3 days, we observed that TREM-2+CD4 ${ }^{+} \mathrm{T}$ cells proliferated more quickly than did TREM-2-CD4 ${ }^{+} \mathrm{T}$ cells (Figure $4 \mathrm{~B}$ ). Since Th1 cells mediate the protective immune response against $M$. tubercu- 

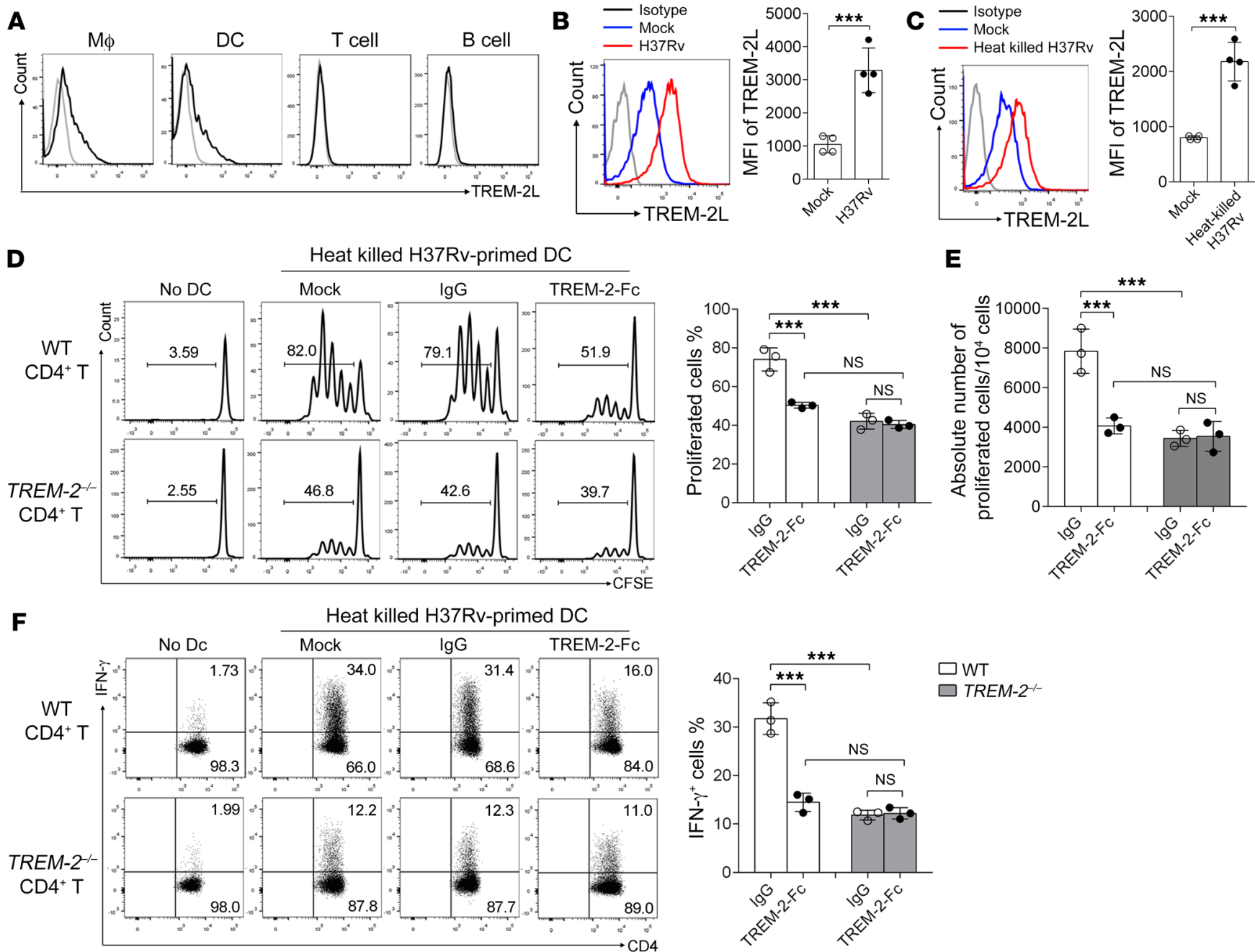

G

Heat killed H37Rv-primed DC
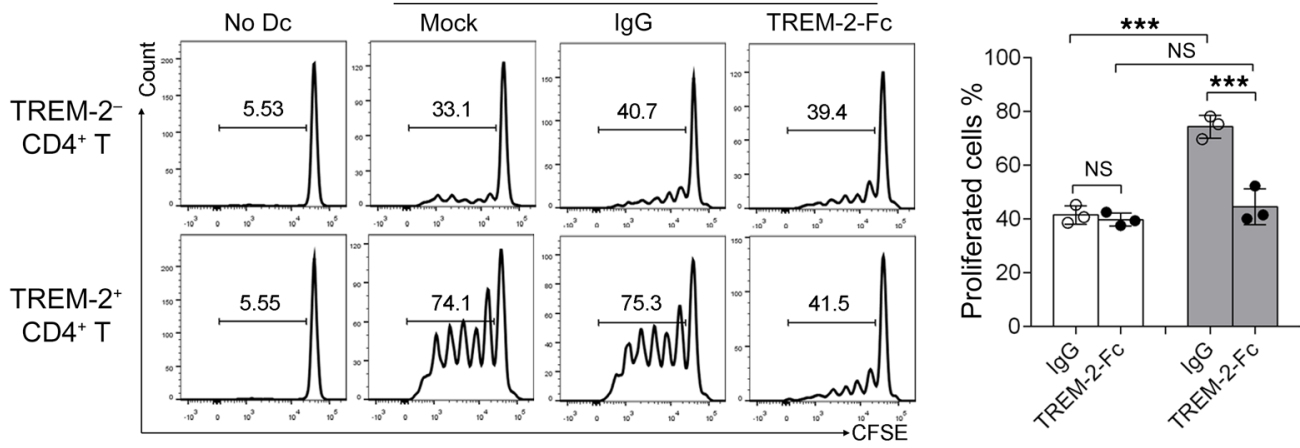

H

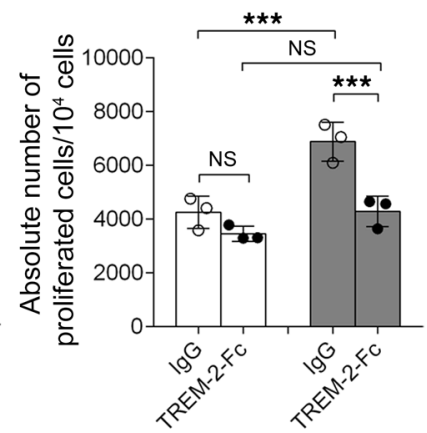

I

Heat killed H37Rv-primed DC
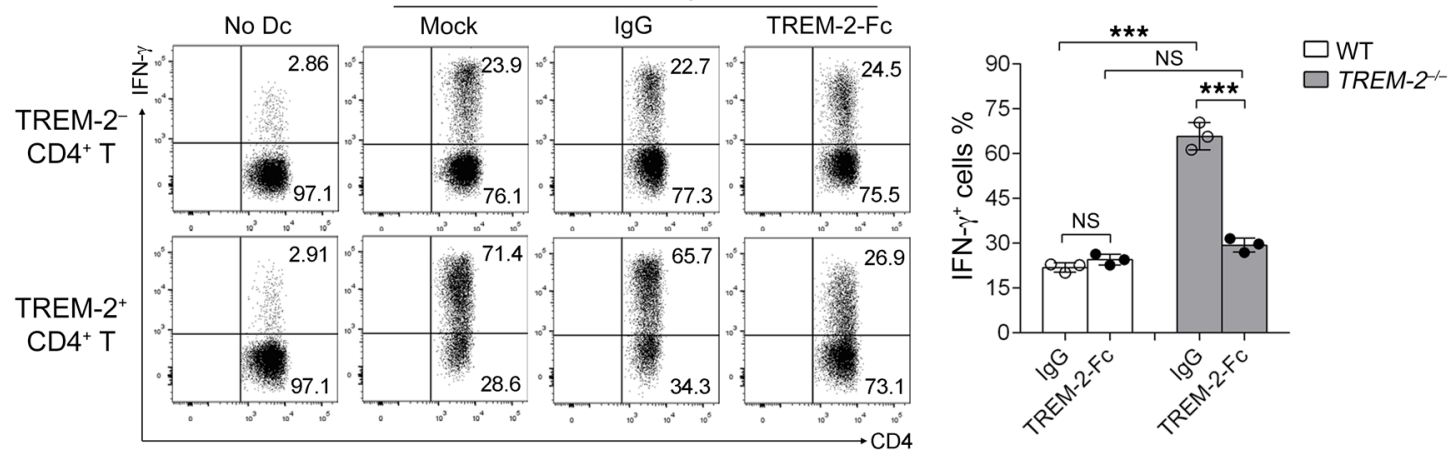
Figure 3. TREM-2 signal induces CD4 ${ }^{+} \mathrm{T}$ cell activation via T cell-APC

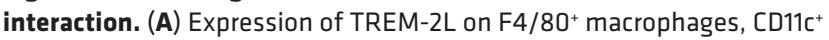
$D C s, C D 3^{+} T$ cells, and $C D 19^{+} B$ cells in spleens of H37Rv-infected mice. (B and C) Expression levels of TREM-2L on DCs were detected after H37Rv infection or heat-killed H37Rv treatment $(n=4)$. (D-F) Splenic T cells sorted from WT or TREM-2-1- mice $(n=3)$ were labeled with CFSE and then cocultured with heat-killed, H37Rv-primed DCs for 5 days in the presence of IgG or mouse TREM-2-Fc protein. The proportion (D) and absolute number $(\mathbf{E})$ of proliferated cells and IFN- $\gamma$ production $(\mathbf{F})$ were assessed by flow cytometry. (G-I) TREM-2+CD4+ versus TREM-2-CD4+ $T$ cells sorted from PBMCs from HCs $(n=3)$ were labeled with CFSE and then cocultured with heat-killed, H37Rv-primed DCs for 5 days in the presence of IgC or human TREM-2-Fc protein. The proportion (G) and absolute number (H) of proliferated cells as well as IFN- $\gamma$ production (I) were assessed by flow cytometry. Data represent the mean \pm SD from at least 3 independent experiments. ${ }^{* *} P<0.001$, by unpaired Student's $t$ test (B and $\mathbf{C}$ ) and 1-way ANOVA (D-I).

losis infection, we next evaluated the role of TREM-2 in modulating Th1 differentiation. PBMCs from patients with active TB were stimulated with $M$. tuberculosis-specific Ag early secreted antigen of $6 \mathrm{kDa}$ (ESAT-6) and $10 \mathrm{kDa}$ culture filtrate protein (CFP-10), or with anti-CD3/anti-CD28 Abs for 12 hours. The flow cytometric data showed that upon restimulation, the production of IFN- $\gamma$, TNF, and IL-2 was increased in TREM-2 $2^{+} \mathrm{CD} 4^{+}$versus TREM-2- $\mathrm{CD} 4^{+} \mathrm{T}$ cells (Figure 4, C-E). Furthermore, the proportions of TNF IFN- $\gamma^{+}$, IFN- $\gamma^{+} \mathrm{IL}-2^{+}$, and TNF$F^{+} \mathrm{IL}-2^{+}$cells were enhanced in TREM- $2^{+} \mathrm{CD} 4^{+}$ versus TREM-2- ${ }^{-} \mathrm{CD} 4^{+} \mathrm{T}$ cells in both patients with active $\mathrm{TB}$ and $\mathrm{HCs}$, and the percentage was much higher in patients with TB than in HCs (Supplemental Figure 9, A-C). In addition, flow cytometric data revealed that the expression of T-bet, a Th1-featured transcription factor, was elevated in TREM-2+CD $4^{+}$versus TREM-2 $\mathrm{CD}^{+} \mathrm{T}$ cells (Supplemental Figure 9D). Taken together, our data suggested that TREM-2 promoted M. tuberculosis-specific CD $4^{+} \mathrm{T}$ cell proliferation and $\mathrm{Th} 1$ differentiation.

TREM-2 interacts with the CD3 $-Z A P 70$ complex to activate $C D 4^{+} T$ cells. Next, we applied IP and liquid chromatographymass spectrometry (LC-MS) to explore the downstream signaling molecules of TREM- 2 in $\mathrm{CD} 4^{+} \mathrm{T}$ cells. The results identified $\mathrm{CD} 3 \zeta$ as a potential protein interacting with TREM- 2 in $\mathrm{CD}^{+} \mathrm{T}$ cells (Supplemental Figure 10A). Anti-TREM-2 or anti-CD3 $\zeta$ IP was performed on WT and TREM-2 ${ }^{-}$mouse $\mathrm{CD} 4^{+} \mathrm{T}$ cells and $\mathrm{F} 4 / 80^{+}$ macrophages, and then immunoblots were analyzed with specific Abs against TREM-2, DAP12, and CD3ל. Our results indicated that TREM-2 interacted with $\mathrm{CD} 3 \zeta$ in $\mathrm{CD}_{4}^{+} \mathrm{T}$ cells, rather than the adaptor molecule DAP12 detected in macrophages (Figure 5, A and B, and Supplemental Figure 10B). Moreover, we trans-

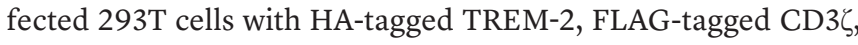
and/or Myc-tagged ZAP70 plasmids and then assessed for protein interaction by IP. We detected surface TREM- 2 expression in 293T cells after transfection with HA-tagged TREM-2 plasmids. Exogenous IP data revealed that TREM-2 interacted with the CD3 3 -ZAP70 complex, but not with $\mathrm{CD} 3 \zeta$ alone (Figure 5, C and D). Endogenous IP data consistently showed that TREM-2 interacted weakly with ZAP70-CD3 $\zeta$ in peripheral $\mathrm{CD} 4^{+} \mathrm{T}$ cells from HCs, but this binding was dramatically strengthened in patients with active TB (Figure 5E). Next, we performed Western blot and flow cytometric analyses to assess the phosphorylation of CD3C (Tyr83) and ZAP70 (Tyr319) in WT versus TREM-2-$\mathrm{CD} 4^{+} \mathrm{T}$ cells. TREM-2 deficiency reduced the phosphorylation of $\mathrm{CD} 3 \zeta$ and ZAP70 in mouse $\mathrm{CD} 4^{+} \mathrm{T}$ cells after anti-CD3/antiCD28 ligation (Figure 5F). Also, we detected higher levels of phosphorylated $\mathrm{CD} 3 \zeta$ (p-CD3ל) (Figure $5 \mathrm{G}$ ) and p-ZAP70 (Figure $5 \mathrm{H})$ in TREM- $2^{+} \mathrm{CD} 4^{+}$versus TREM- $-{ }^{-} \mathrm{CD} 4^{+} \mathrm{T}$ cells from patients with active TB. To confirm whether TREM-2 evokes the activation of $\mathrm{CD} 3 \zeta / \mathrm{ZAP70}$ signaling, we transfected Jurkat cells with TREM-2-expressing plasmids or a PSG5 vector, followed by anti-CD3/anti-CD28 stimulation. We analyzed cell-surface TREM-2 by flow cytometry to confirm the transfection efficiency (Supplemental Figure 11A). Upon stimulation, overexpression of TREM-2 enhanced the phosphorylation of $\mathrm{CD} 3 \zeta$ (Supplemental Figure 11B) and ZAP70 (Supplemental Figure 11C) in Jurkat cells. Together, these data suggested that TREM-2 interacted with the CD3 $\zeta$-ZAP70 complex to induce $\mathrm{T}$ cell activation.

To further explore the critical domains and residues of TREM-2

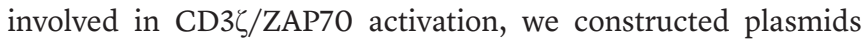
encoding full-length (FL) TREM-2 or the extracellular Ig domain and truncated forms of TREM-2 lacking the transmembrane, the cytosolic domain, and the extracellular Ig domain, respectively (Figure 6A). IP data suggested that truncated TREM-2 with deletion of the cytosolic or Ig domain was able to interact with $\mathrm{CD} 3 \zeta$ / ZAP70, but the Ig domain alone or deletion of the transmembrane domain failed (Figure 6B). These data indicated that TREM-2 interacted with $\mathrm{CD} 3 \zeta /$ ZAP70 through its transmembrane domain. To further determine the critical amino acid sites involved in TREM-2 signaling through CD3 and ZAP70, we further constructed TREM-2 plasmids with the mutations of various conserved residues including C36, R47, C60, T66, and K137, which are located in the extracellular Ig domain or the transmembrane domain and are crucial for the function and signal transduction of TREM-2 (11) (Figure 6C). IP assay data revealed that the K173A mutation dramatically disrupted the interaction between TREM-2

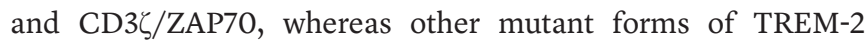
(including C36A, R47H, C60A, and T66M) were still able to interact with CD35/ZAP70 (Figure 6D). In addition, we transfected mouse $\mathrm{CD} 4^{+} \mathrm{T}$ cells with TREM-2-GFP plasmids (WT or mutant forms) or the control vector and then assessed the phosphorylation of $\mathrm{CD} 3 \zeta$ and ZAP70 by flow cytometry in $\mathrm{GFP}^{+}$cells. The flow cytometric data showed that all mutant forms of TREM- 2 reduced

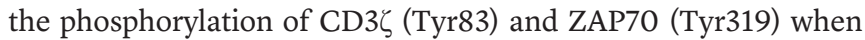
compared with the WT forms (Figure 6, E-I), indicating that the structure integrity of TREM- 2 is important in $\mathrm{CD}^{+} \mathrm{T}$ cell activation. These data suggested that TREM-2 interacted with CD3ל/ ZAP70 via its transmembrane domain (especially the K173 site) and that both the extracellular Ig domain and the transmembrane domain were required for $\mathrm{CD} 4^{+} \mathrm{T}$ cell activation.

TREM-2 activates STAT1/STAT4 to promote Th1 differentiation by interacting with $T$ cell receptor/IFN- $\gamma$ receptor. STAT1 and STAT 4 often form homodimers or heterodimers to induce Th1 differentiation, which is characterized by enhanced T-bet transcription and IFN- $\gamma$ production $(39,40)$. Here, we investigated the role of TREM- 2 on STAT1/STAT 4 activation, T-bet expression, and IFN- $\gamma$ production in human and mouse $\mathrm{CD} 4^{+} \mathrm{T}$ cells. Western blot data showed that overexpression of TREM- 2 in human primary $\mathrm{CD} 4^{+} \mathrm{T}$ cells enhanced STAT1 (Ser727) and STAT4 (Tyr693) phosphoryla- 
A

$\mathrm{HC}$
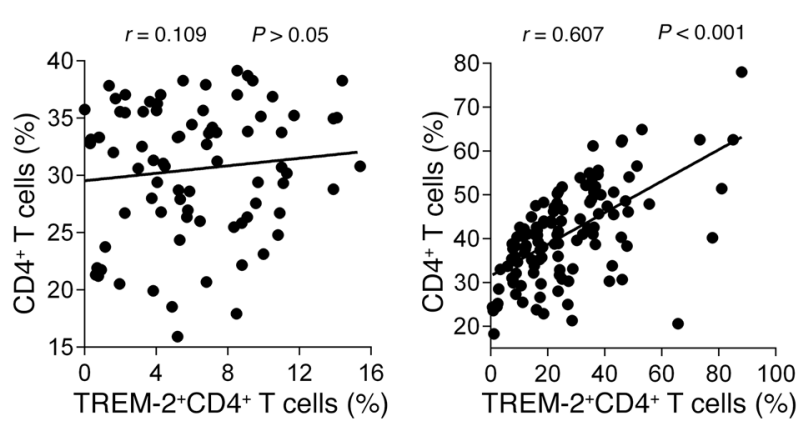

Heat-killed
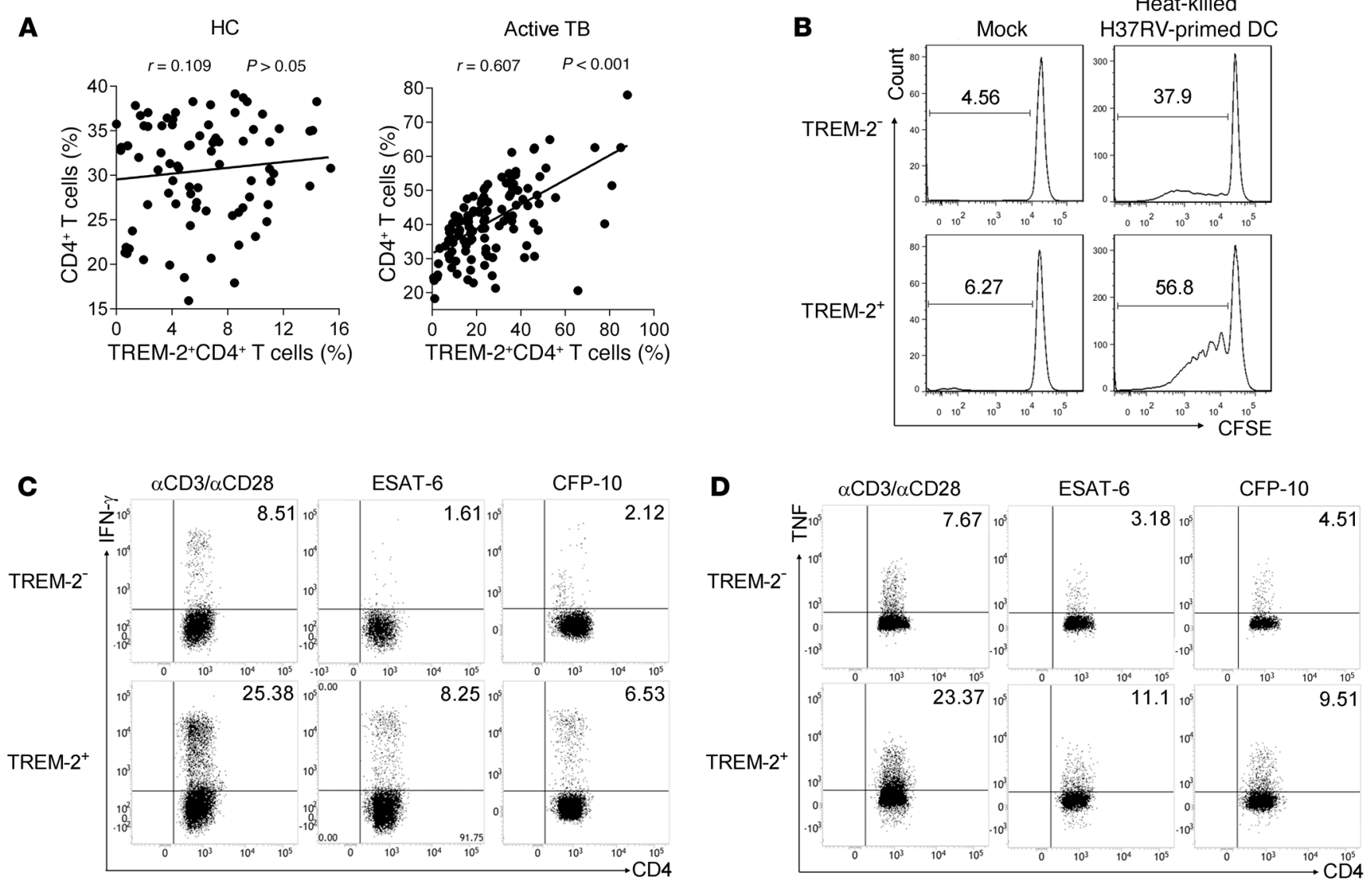

$\alpha \mathrm{CD} 3 / \alpha \mathrm{CD} 28$
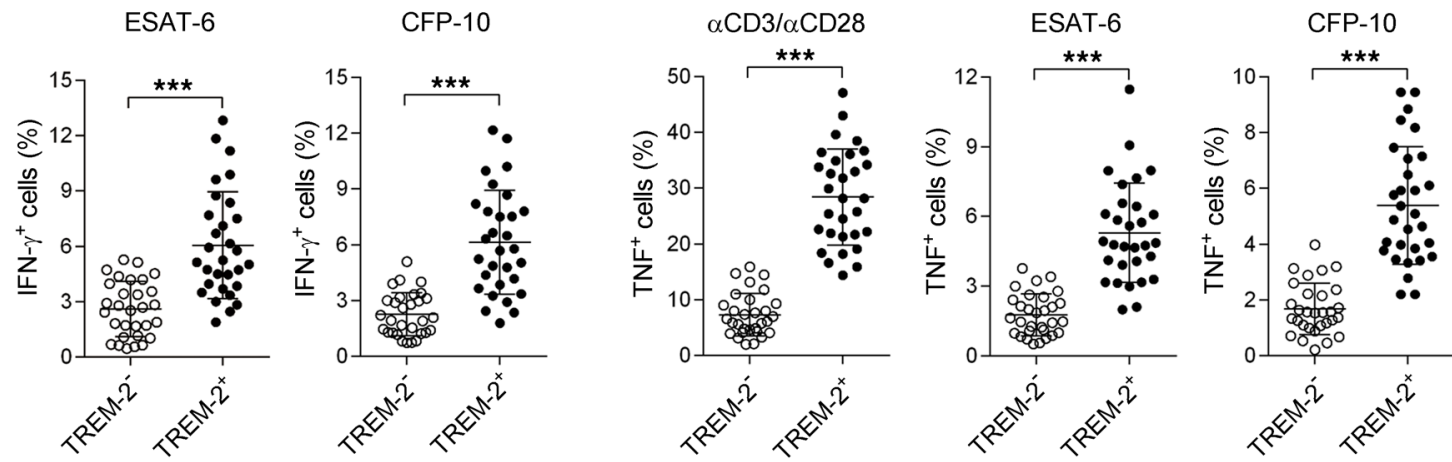
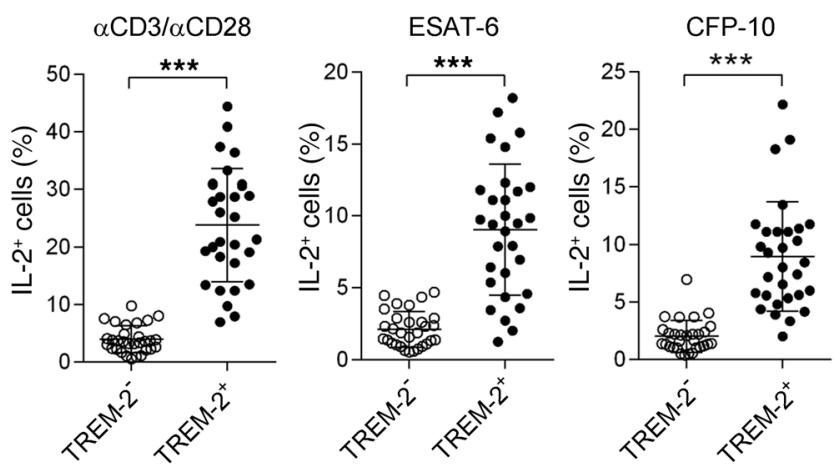
Figure 4. TREM-2 promotes Th1 differentiation of $M$. tuberculosis-specific $\mathbf{C D 4}^{+} \mathbf{T}$ cells in patients with active TB. (A) The correlation between the frequency of $\mathrm{CD}^{+}{ }^{+} \mathrm{T}$ cells and TREM- 2 expression was analyzed in $\mathrm{HCs}(n=$ 81) and patients with active TB $(n=116)$ using SPSS software. $r$, correlation coefficient. (B) CFSE-labeled TREM-2+CD4+ or TREM-2-CD4+ $\mathrm{T}$ cells from patients with active TB were stimulated with heat-killed, H37Rv-primed $\mathrm{DCs}$, and anti-CD3/anti-CD28 $(1 \mu \mathrm{g} / \mathrm{mL})$ for 3 days, and then cell proliferation was assessed by flow cytometry. (C-E) PBMCs from patients with active TB $(n=30)$ were stimulated with anti-CD3/anti-CD28 $(\alpha C D 3 / \alpha C D 28$, $1 \mu \mathrm{g} / \mathrm{mL})$, M. tuberculosis-specific Ag ESAT-6 (10 $\mu \mathrm{g} / \mathrm{mL})$, or CFP-10 (10 $\mu \mathrm{g} /$ $\mathrm{mL}$ ) for 12 hours. The percentages of T cells producing IFN- $\gamma$ (C), TNF (D), and IL-2 (E) in TREM-2+CD4+ or TREM-2-CD4 ${ }^{+}$T cells were detected by flow cytometry. Data represent the mean $\pm \mathrm{SD}$ from at least 3 independent experiments. ${ }^{* *} P<0.001$, by Spearman's correlation analysis for analysis of the correlations in $\mathbf{A}$ and unpaired Student's $t$ test (C-E).

tion (Figure 7A). In addition, TREM-2 deficiency in mouse CD4 ${ }^{+} \mathrm{T}$ cells suppressed the phosphorylation of STAT1 and STAT 4 induced by stimulation with IFN- $\gamma$ and IL-2 plus CD3/CD28 ligation, whereas this effect was compromised by pretreatment with the ZAP70 inhibitor PP2 (Figure 7B). Transfection with plasmids encoding WT TREM-2, but not mutant forms (C36A, R47H, T66M, K173A), enhanced STAT1 and STAT4 phosphorylation (Figure 7, C and D) as well as IFN- $\gamma$ production (Supplemental Figure 12A) in human primary $\mathrm{CD}^{+} \mathrm{T}$ cells upon IFN- $\gamma$ and IL-2 stimulation. Consistently, flow cytometric analysis of primary human $\mathrm{CD} 4^{+} \mathrm{T}$ cells showed that cell proliferation (Supplemental Figure 12B) and IFN- $\gamma$ production (Supplemental Figure 12C) were enhanced in human TREM- $2^{+} \mathrm{CD} 4^{+}$versus TREM-2- $\mathrm{CD} 4^{+} \mathrm{T}$ cells upon stimulation with heat-killed, H37Rv-primed DCs, while this effect was blocked by treatment with the ZAP70 inhibitor PP2 or the pan-STAT inhibitor SH-4-54 (Supplemental Figure 12, B and C).

Previous studies have reported that the IFN- $\gamma$ receptor (IFN$\gamma \mathrm{R}$ ) is an integral part of the T cell receptor (TCR) complex (41). In the present study, we found that TREM-2 interacted with CD3C and the IFN- $\gamma \mathrm{R}$, but not the IL-4R, in $\mathrm{CD} 4^{+} \mathrm{T}$ cells from patients with active TB (Figure 7E). Compared with HCs, we observed increased interaction between TREM- 2 and the IFN- $\gamma$ R in sorted $\mathrm{CD}^{+} \mathrm{T}$ cells from patients with active TB (Figure 7E). To dissociate the effect of the TCR versus the IFN- $\gamma \mathrm{R}$ stimulus, we analyzed the p-STAT1 and p-STAT4 levels in TREM-2+CD4+ ${ }^{+}$cells from patients with active TB upon stimulation with anti-CD3/ anti-CD28 Abs in the presence of anti-IFN- $\gamma$ R-neutralizing Abs. In PBMCs from patients with active TB, higher levels of p-STAT1 (Ser727) and p-STAT4 (Tyr693) were detected by flow cytometry in TREM-2 ${ }^{+} \mathrm{CD} 4^{+} \mathrm{T}$ cells versus TREM- ${ }^{-} \mathrm{CD} 4^{+} \mathrm{T}$ cells (Figure $7, \mathrm{~F}$ and $\mathrm{G}$ ). Treatment with anti-IFN- $\gamma \mathrm{R}$-neutralizing Abs reduced the phosphorylation of STAT1 and STAT4 in TREM- $2^{+} \mathrm{CD} 4^{+} \mathrm{T}$ cells, but not in TREM-2 $\mathrm{CD}^{+} \mathrm{T}$ cells (Figure $7, \mathrm{~F}$ and $\mathrm{G}$ ), indicating that TREM-2 activated STAT1 and STAT 4 signaling by interacting with the TCR-IFN- $\gamma$ R complex.

Furthermore, we analyzed T-bet expression in sorted human TREM $-2^{+} \mathrm{CD} 4^{+}$and TREM- ${ }^{-} \mathrm{CD} 4^{+} \mathrm{T}$ cells upon Th1 polarization in the presence of anti-IFN- $\gamma$ R-neutralizing Abs. We detected higher levels of T-bet expression by flow cytometry in TREM- $2^{+} \mathrm{CD} 4^{+}$ versus TREM-2-CD4 ${ }^{+} \mathrm{T}$ cells (Figure $7 \mathrm{H}$ ). Blocking the IFN- $\gamma \mathrm{R}$ reduced T-bet expression in TREM- $2^{+} \mathrm{CD} 4^{+} \mathrm{T}$ cells compared with the IgG control (Figure $7 \mathrm{H}$ ). These results together suggested that
TREM-2 promoted CD4 ${ }^{+} \mathrm{T}$ cell proliferation and Th1 differentiation via STAT1 and STAT4 signaling.

TREM-2 promotes Th1-mediated host defense against $M$. tuberculosis infection. To determine whether TREM-2 influences CD4 ${ }^{+}$ T cell-mediated antimycobacterial defense in vivo, we transferred

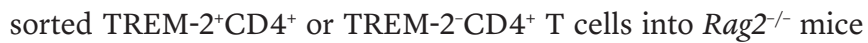
i.v., followed by infection with the M. tuberculosis strain H37Rv. We first assessed the stability of TREM- 2 expression on the CD $4^{+} \mathrm{T}$ cell surface by flow cytometry. Rag $2^{-/-}$mice were transferred with mixed TREM-2-CD45.1 $1^{+} \mathrm{CD} 4^{+}$and TREM $-2^{+} \mathrm{CD} 45.2^{+} \mathrm{CD} 4^{+} \mathrm{T}$ cells at a ratio of 1:1, followed by $\mathrm{H} 37 \mathrm{Rv}$ infection. The data showed that approximately $99 \%$ of CD $45.2^{+} \mathrm{T}$ cells maintained the TREM- $2^{+}$ phenotype both 24 hours after adoptive transfer and 7 days p.i. (Supplemental Figure 13, A and B). Furthermore, approximately 99\% of CD $45.1^{+} \mathrm{T}$ cells maintained the TREM-2 phenotype 24 hours after adoptive transfer (Supplemental Figure 13A), whereas on day 7 p.i., approximately $20 \%$ of CD $45.1^{+} \mathrm{T}$ cells converted to the TREM-2 ${ }^{+}$phenotype (Supplemental Figure 13B).

Next, we assessed the host immune response against $M$. tuberculosis in $\mathrm{Rag} 2^{-/-}$recipient mice reconstituted with $\mathrm{TREM}-2^{+}$or TREM $-2^{-} \mathrm{CD} 4^{+} \mathrm{T}$ cells. As expected, we observed that TREM-2+ $\mathrm{CD} 4^{+} \mathrm{T}$ cells proliferated more quickly than did TREM-2 $\mathrm{CD} 4^{+} \mathrm{T}$ cells, both in vivo (Supplemental Figure 14, A and B) and in vitro (Supplemental Figure 14C). We observed increased IFN- $\gamma$, TNF, and IL-2 production (Supplemental Figure 14D) in $\mathrm{CD}^{+} \mathrm{T}$ cells from mice transferred with TREM-2 ${ }^{+} \mathrm{CD} 4^{+} \mathrm{T}$ cells as detected by flow cytometry, and ELISA data further confirmed increased Th1 cytokine production in the lungs, spleens, and blood of TREM-2+ $\mathrm{CD}^{+} \mathrm{T}$ cell-transferred mice (Supplemental Figure 14E). Moreover, transfer of TREM $-2^{+} \mathrm{CD} 4^{+} \mathrm{T}$ cells significantly reduced the bacterial burden in the lungs and spleens of recipient mice 4 and 6 weeks p.i. (Supplemental Figure 14F) and resulted in reduced lung damage and granuloma formation in the infected mice by 28 days p.i. (Supplemental Figure 14G).

We further determined the in vivo role of TREM-2 in CD4 $4^{+} \mathrm{T}$ cell-mediated host responses against $M$. tuberculosis by transfer-

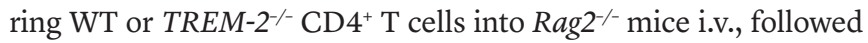
by H37Rv infection (Figure 8A). Consistent with the results from the transfer model of TREM $-2^{+} \mathrm{CD} 4^{+}$versus TREM $-2^{-} \mathrm{CD} 4^{+} \mathrm{T}$ cells, we observed decreased frequencies of $\mathrm{CD} 4^{+} \mathrm{T}$ cells in the lungs and spleens of recipient $R a g 2^{-/-}$mice after TREM-2-/ CD $4^{+} \mathrm{T}$ cell transfer (Figure $8 \mathrm{~B})$. An in vitro proliferation assay also demonstrated that WT CD4 ${ }^{+} \mathrm{T}$ cells proliferated more quickly than did TREM$2^{--} \mathrm{CD}^{+} \mathrm{T}$ cells upon stimulation with heat-killed, H37Rv-primed DCs (Figure 8C). Furthermore, lower levels of IFN- $\gamma$, TNF, and IL-2 production (Figure 8D and Supplemental Figure 15A) as well as decreased T-bet expression levels (Supplemental Figure 15B) in splenic $\mathrm{CD}^{+} \mathrm{T}$ cells were detected in the infected $\mathrm{Rag}^{-{ }^{--}}$mice transferred with TREM-2-- CD4 ${ }^{+} \mathrm{T}$ cells. ELISA further confirmed the reduced production of Th1 cytokines (Figure 8E). Moreover, we detected an increased bacterial load (Figure $8 \mathrm{~F}$ ) and aggravated lung injury (Figure 8G) after the transfer of TREM-2-/- CD $4^{+} \mathrm{T}$ cells.

To exclude the possibility that the absence of other immune cells in $\mathrm{Rag}^{-{ }^{-/}}$mice may affect $\mathrm{CD} 4^{+} \mathrm{T}$ response, we next established a bone marrow (BM) chimeric mouse model to verify the direct effect of TREM- 2 on CD4 ${ }^{+} \mathrm{T}$ cells. Rag2 $2^{--}$mice transferred with a mixture of WT and TREM-2-/- BM cells at a ratio of $1: 1$ were 
A
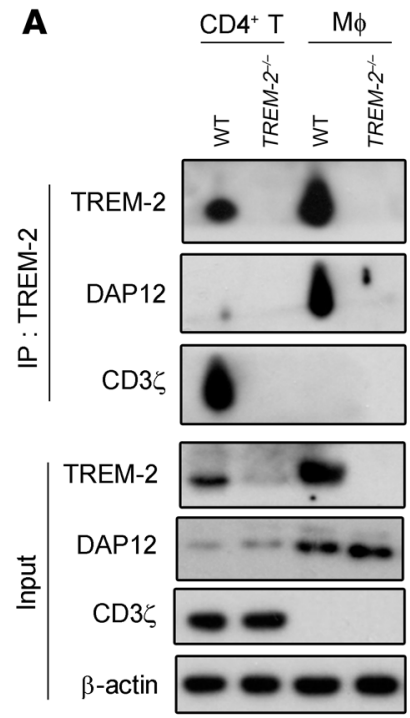

E

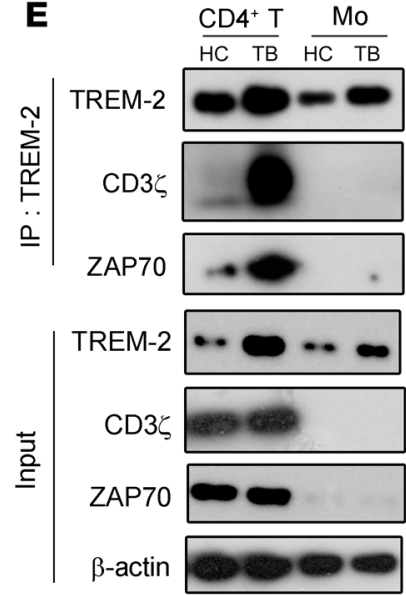

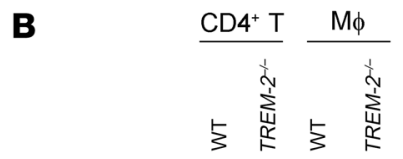
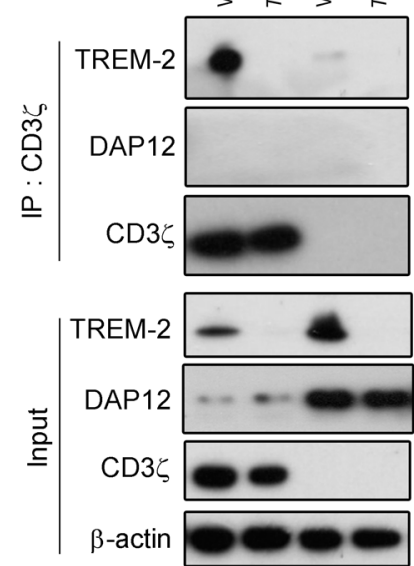

$\mathbf{F}$

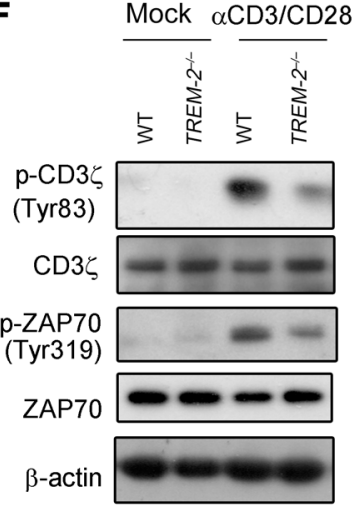

C
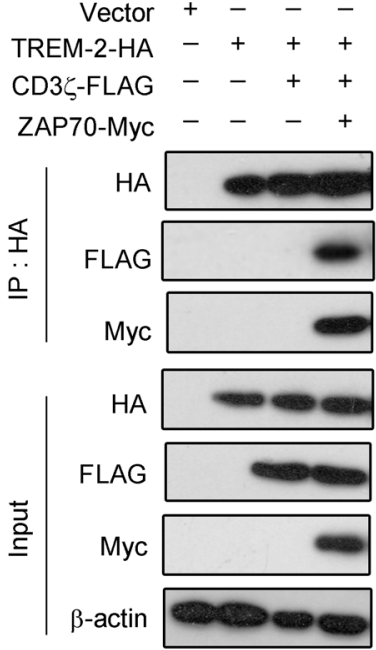

G
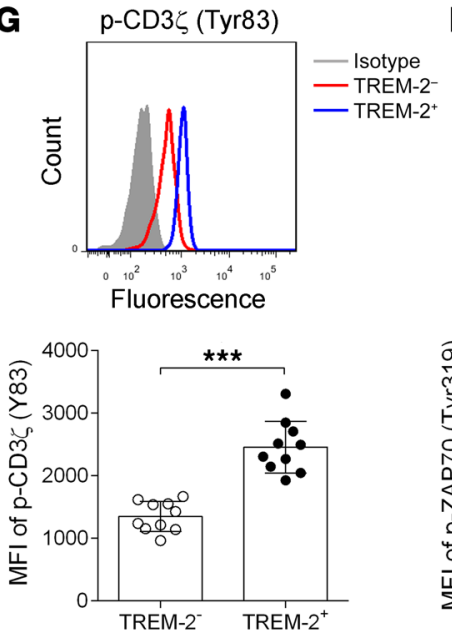
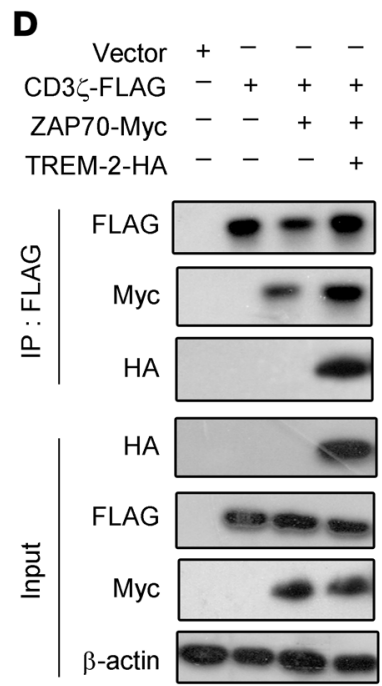

H
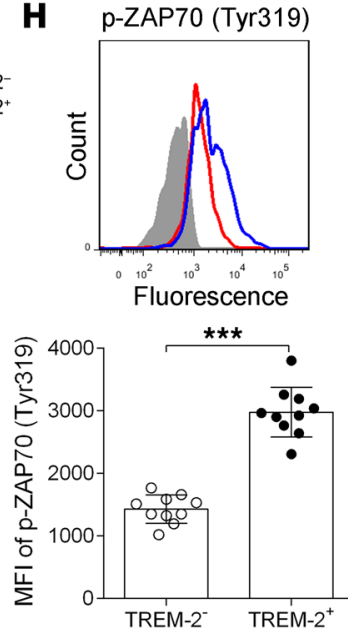

Figure 5. TREM-2 interacts with CD3 $/$ /ZAP70 to enhance TCR signaling. (A and B) Naive CD4+ $4^{+}$cells isolated from WT or TREM-2//- mice were treated with anti-CD3 $\mathrm{mAb}(1 \mu \mathrm{g} / \mathrm{mL})$ for 30 minutes. F4/80+ macrophages treated with LPS ( $1 \mu \mathrm{g} / \mathrm{mL}$, 30 min) were used as a control. Cell lysates (input), anti-

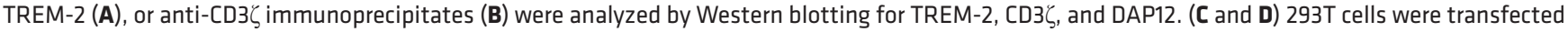
with a PSG5 vector containing HA-tagged TREM-2, FLAG-tagged CD3 , and Myc-tagged ZAP70. Blots of cell lysates (input) or anti-HA (C) and anti-FLAG (D) immunoprecipitates were analyzed by Western blotting for HA, FLAG, and Myc. (E) Human CD4+ ${ }^{+}$cells or CD11 ${ }^{+}$monocytes were sorted from PBMCs from HCs or patients with active TB. Anti-TREM-2 immunoprecipitates were analyzed for CD3 $\zeta$ and ZAP70. (F) WT versus TREM-2-/- mouse CD4+ T cells

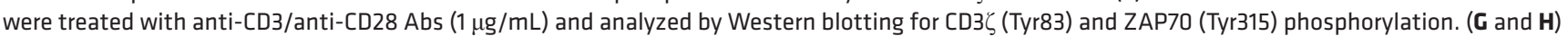

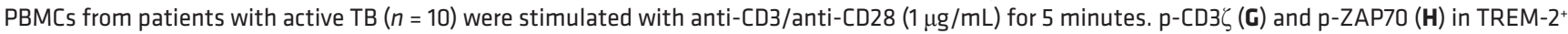
$\mathrm{CD}^{+}$versus TREM-2-CD4+ $\mathrm{T}$ cells were analyzed by flow cytometry. Data are shown as the MFI of the indicated molecules and represent the mean \pm SD from at least 3 independent experiments. ${ }^{* *} P<0.001$, by unpaired Student's $t$ test $(\mathbf{G}$ and $\mathbf{H}$ ). M $\phi$, macrophages.

infected i.v. with H37Rv and then assessed for Th1 responses. The results showed that $\mathrm{CD} 4^{+} \mathrm{T}$ numbers were significantly increased in recipient mice after $\mathrm{H} 37 \mathrm{Rv}$ infection, in which over $75 \%$ of $\mathrm{CD} 4^{+}$ $\mathrm{T}$ cells were derived from WT (CD45.1) BM cells, whereas only 25\% were from TREM-2-- (CD45.2) BM cells (Supplemental Figure 16A). We consistently found that WT-derived $\mathrm{CD}^{+} \mathrm{T}$ cells had higher expression levels of the activation markers CD69 and CD25 (Supplemental Figure 16, B and C) and increased production of Th1 cytokines including IFN- $\gamma$, TNF, and IL-2 (Supplemental Figure 16, D-F) when compared with TREM-2/--derived CD4 $4^{+} \mathrm{T}$ cells.

Finally, to further elucidate the intrinsic role of TREM-2 on the $\mathrm{CD}^{+} \mathrm{T}$ cell response against M. tuberculosis, CD4-specific
TREM-2 conditional KO mice (TREM- $2^{f / f l} \mathrm{CD} 4$-Cre) were generated by crossing mice with loxP-flanked alleles of TREM-2 exons 2 and $3\left(T R E M-2^{f / f l}\right)$ and mice with transgenic expression of Cre recombinase driven by the gene encoding CD4 (CD4-Cre) (Supplemental Figure 17). TREM-2 $2^{f / f l}$ and TREM-2fl/fl CD4-Cre mice were infected i.v. with H37Rv. We detected reduced frequencies of $\mathrm{CD}^{+} \mathrm{T}$ cells in the lungs and spleens (Figure 9A) as well as impaired production of IFN- $\gamma$, TNF, and IL-2 (Figure 9, B and C) in TREM- $2^{f / f l} \mathrm{CD} 4-\mathrm{Cre}$ mice compared with control TREM-2 $2^{f / f l}$ mice 28 days p.i. Moreover, survival of TREM-2 ${ }^{f / f l}$ CD4-Cre mice was reduced (Figure 9D), with increased bacterial loads in the lungs and spleens (Figure 9E) and accelerated lung injury (granuloma 
A

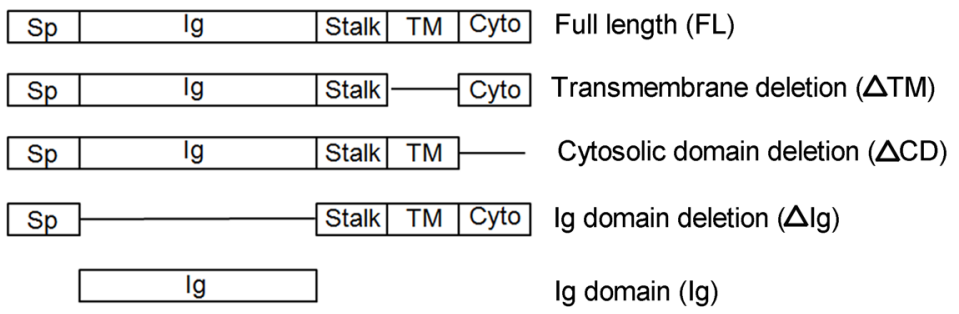

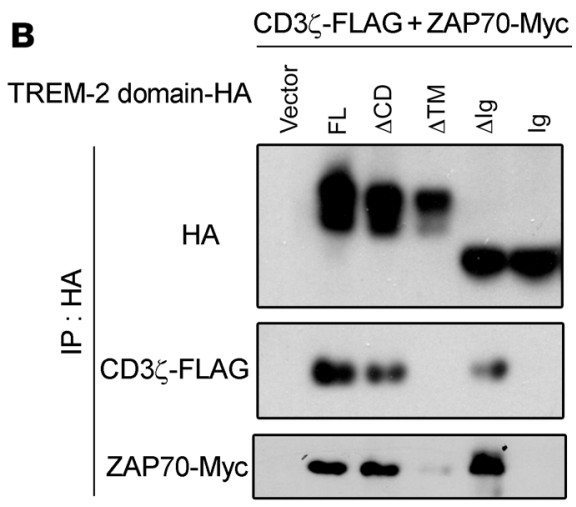
TREM-2
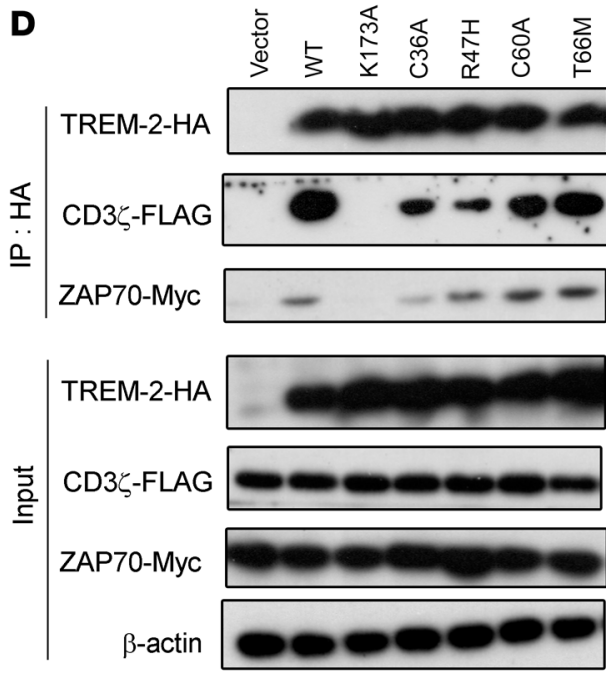

\section{$\mathbf{E}$}

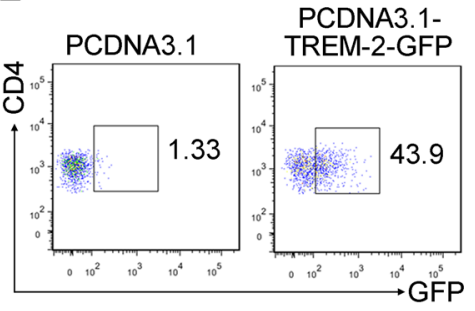

F $\mathrm{p}-\mathrm{CD} 3 \zeta(\mathrm{Tyr} 83)$

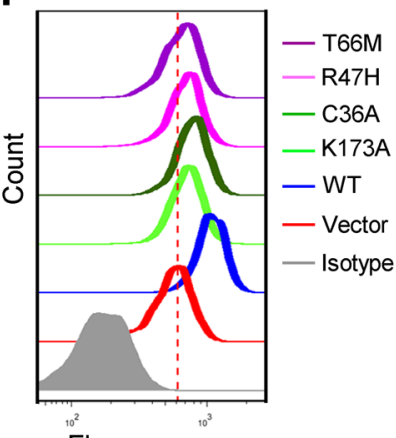

Fluorescence

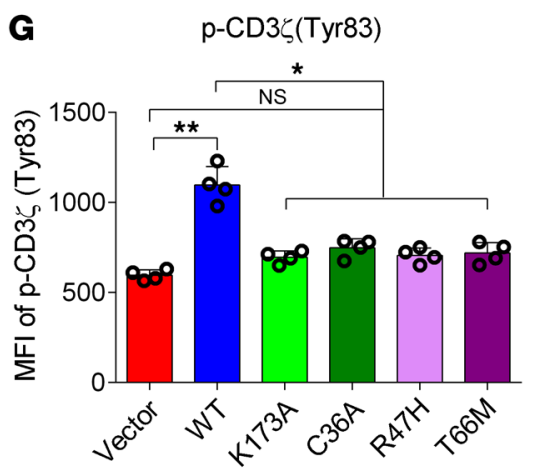

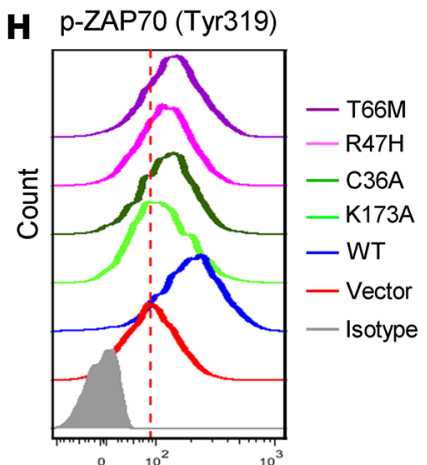

Fluorescence

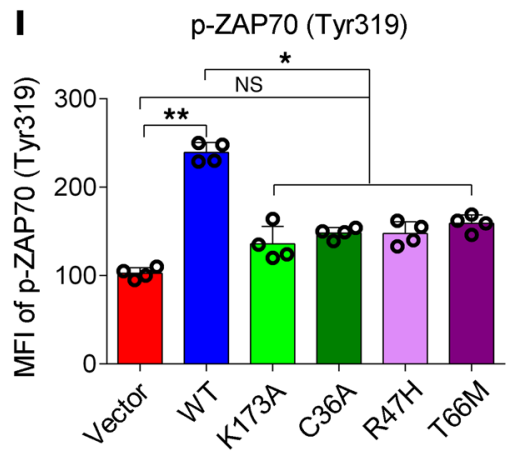

Figure 6. TREM-2 activates CD3 $\zeta / Z A P 70$ signaling via its transmembrane and Ig domain. (A-D) A PSG5 plasmid encoding the Ig domain, WT (FL), or truncated forms of TREM-2, respectively, deleting $\mathrm{Ig}(\Delta \mathrm{Ig})$, the transmembrane $(\triangle T M)$, or the cytosolic domain $(\Delta C D)$, as well as 5 mutant forms of TREM-2 (C36A, R47H, C60A, T66M, and K173A) were constructed. (B and D) 293T cells were transfected with truncated or mutant TREM-2 plasmids. A co-IP assay was performed to analyze the interaction among TREM-2, CD3 , and ZAP70. (E-I) Sorted CD4 ${ }^{+}$T cells $(n=4)$ were transfected with mutant TREM-2-CFP plasmids. CD3 (Tyr83) and ZAP70 (Tyr319) phosphorylation was analyzed in GFP+ cells by flow cytometry. Data represent the mean \pm SD from at least 3 independent experiments. ${ }^{*} P<0.05$ and ${ }^{* *} P<0.01$, by 1 -way ANOVA $(\mathbf{G}$ and $\mathbf{I})$. 


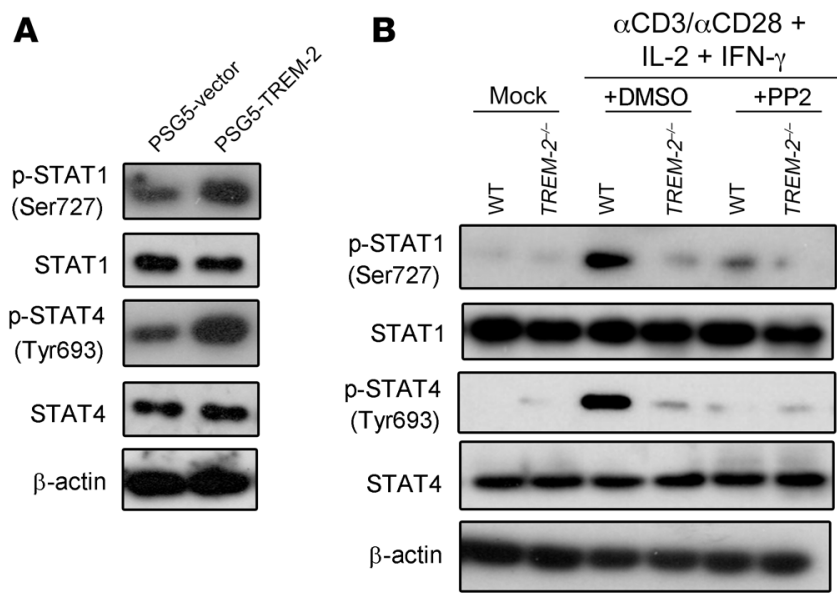

C
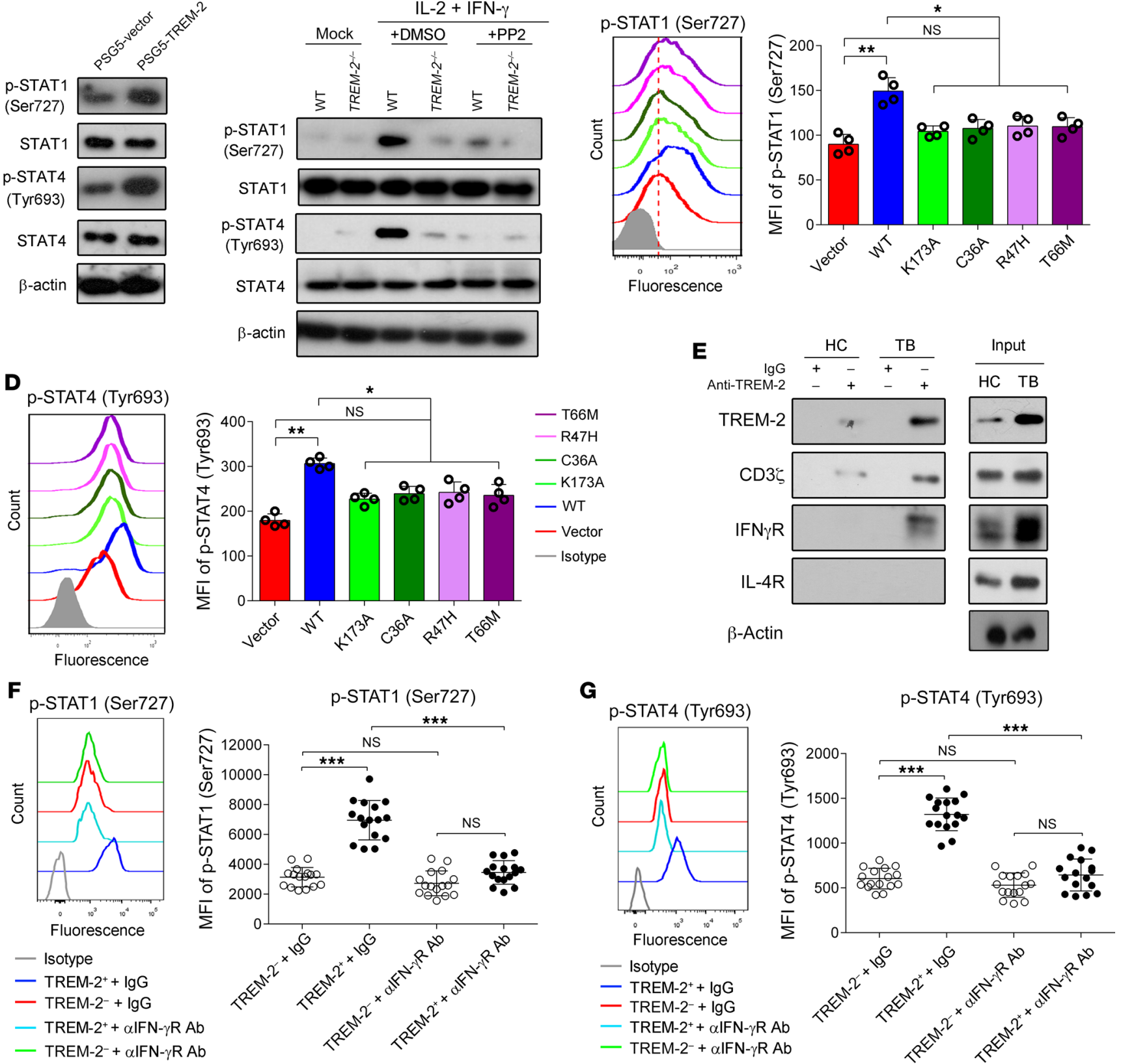

H
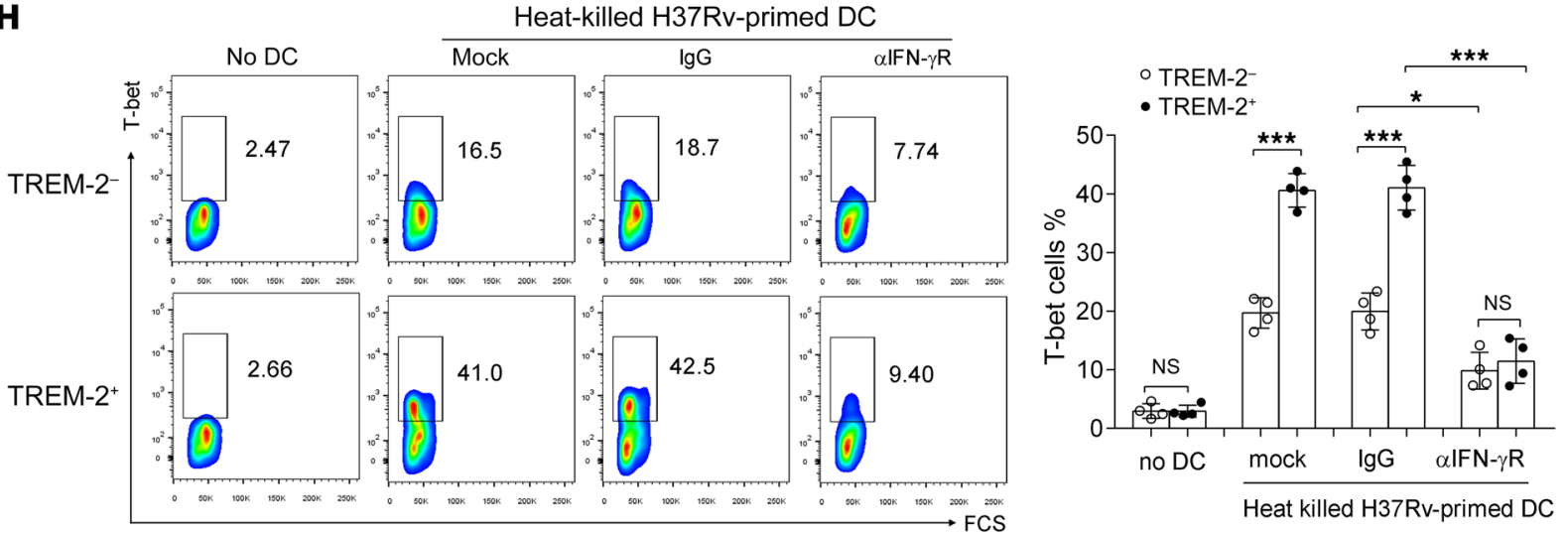
Figure 7. TREM-2 promotes STAT1 and STAT4 activation by interacting with IFN- $\gamma \mathbf{R}$. (A) Sorted human CD4+ T cells were transfected with PSG5TREM-2 plasmids for 24 hours and then stimulated with anti-CD3/antiCD28 Abs. STAT1 and STAT4 phosphorylation was analyzed by Western blotting. (B) Mouse WT versus TREM-2-1- CD4 ${ }^{+} T$ cells were stimulated with anti-CD3/anti-CD28 Abs $(1 \mu \mathrm{g} / \mathrm{mL})$ plus IL-2 $(10 \mathrm{ng} / \mathrm{mL})$ and IFN- $\gamma(20 \mathrm{ng} /$ $\mathrm{mL})$ for 30 minutes in the presence of PP2 $(1 \mu \mathrm{M})$ or DMSO control. STAT1 and STAT4 phosphorylation was determined by Western blotting. (C and D) Primary human CD4+ ${ }^{+}$cells $(n=4)$ were transfected with WT or mutant forms of TREM-2-GFP plasmids. STAT1 and STAT4 phosphorylation was analyzed in $\mathrm{GFP}^{+}$cells by flow cytometry. (E) Human CD4 ${ }^{+} \mathrm{T}$ cells from PBMCs from patients with active TB were sorted. Anti-TREM-2 immunoprecipitates were analyzed for IFN- $\gamma \mathrm{R}, \mathrm{IL}-4 \mathrm{R}$, and $\mathrm{CD} 3 \zeta$. (F and $\mathbf{G}$ ) PBMCs from patients with active TB $(n=16)$ were stimulated with anti-CD3/antiCD28 Abs $(1 \mu \mathrm{g} / \mathrm{mL})$ in the presence of anti-IFN- $\gamma \mathrm{R}$ Abs $(20 \mu \mathrm{g} / \mathrm{mL})$. STAT1 (Ser727) and STAT4 (Tyr693) phosphorylation in TREM-2+ or TREM-2 CD4 ${ }^{+} \mathrm{T}$ cells was analyzed by flow cytometry, and the MFI of p-STAT1 and p-STAT4 was quantified. (H) Human TREM- $2^{+} \mathrm{CD} 4^{+}$versus TREM-2-CD4+ $\mathrm{T}$ cells $(n=4)$ were stimulated with heat-killed, H37Rv-primed DCs for 3 days in the presence of IgG or anti-IFN- $\gamma \mathrm{R}$ Abs $(20 \mu \mathrm{g} / \mathrm{mL})$. Data represent the mean \pm SD from at least 3 independent experiments. ${ }^{*} P<0.05$, ${ }^{*} P<0.01$, and ${ }^{* *} P<0.001$, by 1 way ANOVA $(\mathbf{C}-\mathbf{H})$.

formation) (Figure 9F) compared with TREM-2 $2^{\text {f/fl }}$ control mice. Taken together, these data demonstrated that TREM-2 in CD4 $4^{+}$ $\mathrm{T}$ cells promoted proinflammatory Th1 responses and bacterial clearance during in vivo M. tuberculosis infection.

\section{Discussion}

TREM-2 is initially identified as an innate receptor on myeloid cells. A previous study reported that TREM- 2 is expressed in CD4 ${ }^{+}$ and $\mathrm{CD}^{+} \mathrm{T}$ cells from patients with $\mathrm{TB}$ (26). In the present study, we found that the percentage of peripheral TREM-2 $2^{+} \mathrm{CD} 4^{+} \mathrm{T}$ cells was upregulated in patients with active TB versus HCs. Although peripheral TREM-2 $2^{+} \mathrm{CD} 8^{+} \mathrm{T}$ cells were also enhanced in patients with active $\mathrm{TB}$, the correlation with disease progression was much weaker than that of TREM- $-2^{+} \mathrm{CD} 4^{+} \mathrm{T}$ cells. Furthermore, we found that TREM-2 expression on $\mathrm{CD} 4^{+} \mathrm{T}$ cells was positively associated with the expression of CD25, CD69, CD44, and CXCR3. CD25 and CD69 appear to be the earliest inducible cell-surface molecules acquired during $\mathrm{T}$ cell activation (42). The adhesion molecule CD44 and chemokine receptor CXCR3 are critical for lymphocyte migration to inflamed tissues (43). Besides, TREM-2 ${ }^{+} \mathrm{CD} 4^{+}$ $\mathrm{T}$ cells displayed more effector memory phenotypes as defined by CD45RO plus CCR7 or CD27. The chemokine receptor CCR7 and the TNF receptor superfamily member $\mathrm{CD} 27$ are $\mathrm{T}$ cell differentiation markers that are commonly used as comarkers for Tcm cells $(44,45)$. Although Tcm cells could be defined as early memory $\left(\mathrm{CD} 45 \mathrm{RO}^{+} \mathrm{CCR} 7^{-} \mathrm{CD} 27^{+}\right) \mathrm{T}$ cell subsets and effector memory $\left(\mathrm{CD} 45 \mathrm{RO}^{+} \mathrm{CCR} 7^{-} \mathrm{CD} 27^{-}\right)$subsets, the difference between $\mathrm{CD} 27$ and CCR7 is ignorable in distinguishing Tcm cells $(46,47)$. Collectively, these data indicated that TREM-2 might play an essential role in T cell-mediated host defense against $M$. tuberculosis infection.

A previous study indicated that TREM-2L was expressed on the surface of macrophages (5). Here, we found that TREM-2L expression was increased in $M$. tuberculosis-infected macrophages and DCs. Blockage of TREM-2L-TREM-2 interaction by the TREM-2-Fc fusion protein reduced the proliferation and IFN- $\gamma$ production of $\mathrm{CD}^{+}{ }^{+} \mathrm{T}$ cells. However, which ligand of TREM-2 on APCs is involved in the modulation of $\mathrm{CD}^{+} \mathrm{T}$ cell activity remains unknown and thus requires further exploration. In addition, TREM- 2 promoted $\mathrm{CD} 4^{+} \mathrm{T}$ cell proliferation and Th1 differentiation in both humans and mice. It is reported that infectious or inflammatory stimuli may induce the expression of certain TLRs on the $\mathrm{T}$ cell surface, which in turn modulate $\mathrm{T}$ cell activation and effector differentiation (1). For example, $\mathrm{CD} 4^{+} \mathrm{T}$ cells from patients with TB pleurisy showed increased TLR2 expression levels compared with levels in HCs, and activation of TLR2 by stimulation with M. tuberculosis $19 \mathrm{kDa}$ lipoprotein induces IFN- $\gamma$ production in $\mathrm{CD}^{+} \mathrm{T}$ cells (48). Moreover, TLT2 on the $\mathrm{CD} 8^{+} \mathrm{T}$ cell surface functions as the counter-receptor for the costimulatory molecule B7-H3 and enhances IFN- $\gamma$ and IL-2 production in $\mathrm{CD} 8^{+}$ $T$ cells (25). Therefore, we speculate that TREM-2 may function as a costimulatory molecule on $\mathrm{CD} 4^{+} \mathrm{T}$ cells, triggering Th1 responses and host inflammation.

We next explored the signal transduction mechanism of TREM-2-mediated T cell activation. We performed IP and LC-MS experiments to identify $\mathrm{CD} 3 \zeta$ as the potential molecule that interacts with TREM-2. It is well known that the Ag-specific signal via the TCR induces the phosphorylation of immunoreceptor tyrosine-based activation motif (ITAM) on CD3 chains, particularly the $\mathrm{CD} 3 \zeta$, and then recruits the kinase ZAP70 to the phosphorylated ITAMs (49). Activated ZAP70 in turn phosphorylates and activates various downstream signal transduction molecules, leading to $\mathrm{T}$ cell activation (50). We demonstrated that TREM-2, rather than DAP12 (the adaptor molecule reported in macrophages), interacted with the $\mathrm{CD} 3 \zeta$-ZAP70 complex in $\mathrm{CD} 4^{+} \mathrm{T}$ cells and that this interaction was dramatically strengthened in patients with $\mathrm{TB}$ versus HC donors. These data indicated that TREM-2 interacted

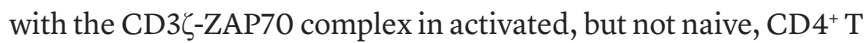
cells and supported the findings that TREM-2 expression was positively related with $\mathrm{T}$ cell activation phenotype.

Next, we examined the key domain or residues in TREM-2mediated T cell activation. TREM-2 has an extracellular Ig-like ligand-binding domain and a transmembrane region bearing a positively charged lysine $(\mathrm{K})$ residue that interacts with DAP12 (11). We analyzed the amino acid sequence of $\mathrm{CD} 3 \zeta$ and found a negatively charged aspartic acid (D) residue at the 31-51 region (LCYLLDGILFIYGVILTALFL) of the transmembrane domain, similar to DAP12, which indicated a possible interaction with the positively charged lysine (K) residue on the TREM-2 transmembrane domain (11). Numerous studies have demonstrated that the loss-of-function mutations of TREM-2 (e.g., R47H and T66M) impair the survival, phagocytosis, and lipid metabolism of microglial cells, leading to the onset of neurodegenerative diseases $(51,52)$. Except for the R47H and T66M mutations that are widely reported, K173 and C36 are also key amino acids indispensable for TREM-2 signal transduction (11). The interaction of TREM-2 with its adaptor DAP12 depends on the lysine-aspartate electrostatic interaction mediated by K173 (11). In the present

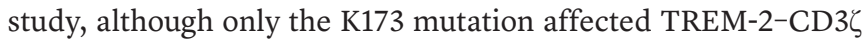
interaction, the activation of CD3ל/ZAP70/STAT1/STAT4 signaling in T cells was suppressed by all of the TREM-2 mutants mentioned above, including C36A, R47H, C60A, T66M, and $\mathrm{K} 173$, indicating the importance of the structural integrity of TREM- 2 in $\mathrm{CD} 4^{+} \mathrm{T}$ cell activation. 
A

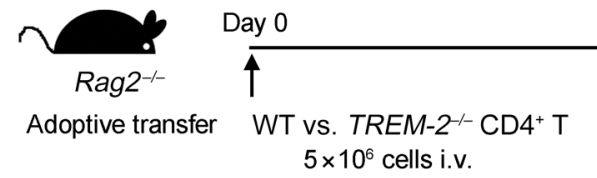

Day 28

Mtb plate count

Histopathology

Flow cytometry

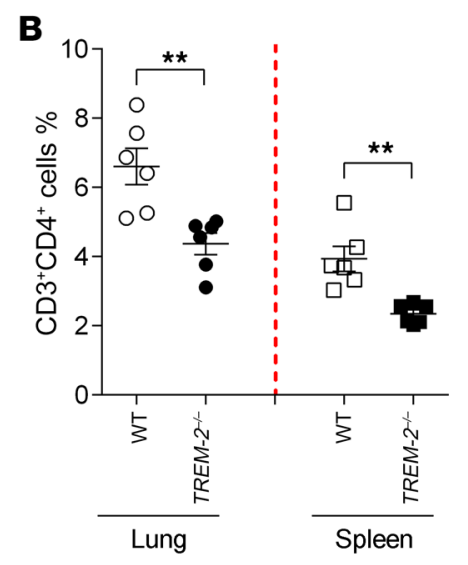

C

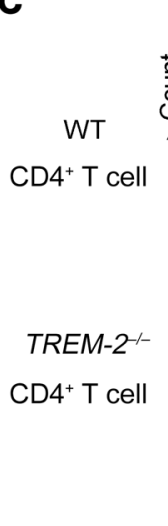

$1 \times 10^{6}$ CFU i.p.
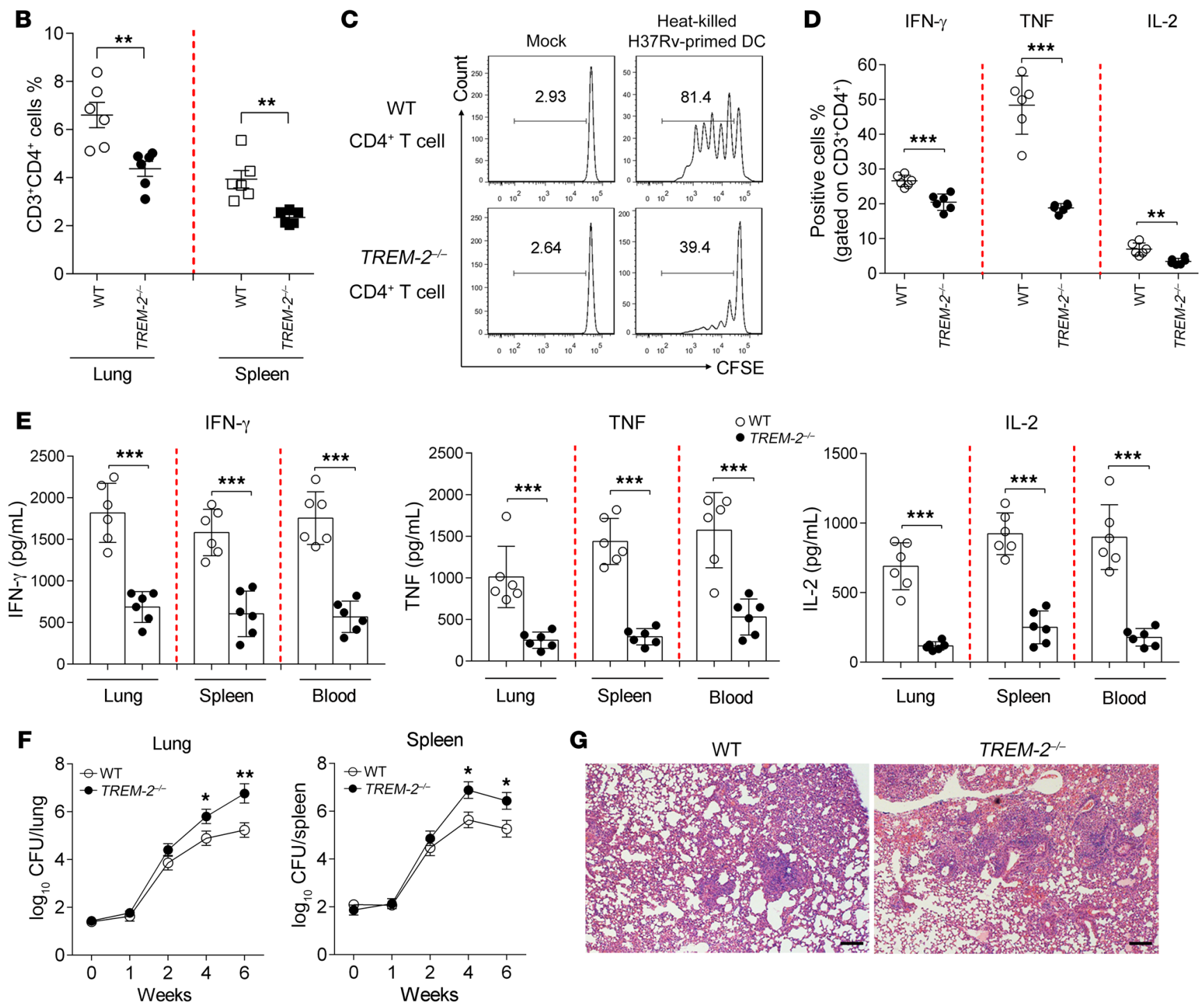

G

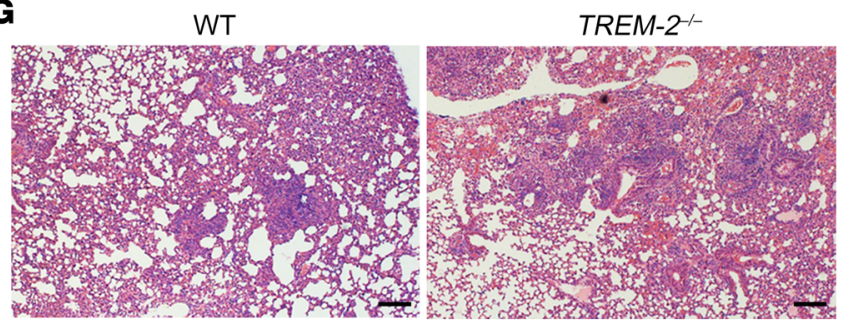

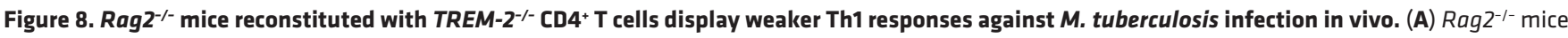
$(n=6)$ were injected i.v. with $5 \times 10^{6}$ WT or TREM-2-/- CD4 ${ }^{+}$T cells, followed by i.p. injection of $1 \times 10^{6}$ CFU H37Rv. On day 28 p.i., lungs and spleens were collected. (B) The frequency of pulmonary and splenic CD4+ T cells was determined by flow cytometry. (C) CFSE-labeled WT or TREM-2-/- CD4 ${ }^{+}$T cells were stimulated with heat-killed, H37Rv-primed DCs, and anti-CD3/anti-CD28 Abs $(1 \mu \mathrm{g} / \mathrm{mL})$ for 3 days, and then cell proliferation was assessed by flow cytometry. (D) Splenocytes were stimulated with PMA $(50 \mathrm{nM})$, ionomycin $(1 \mu \mathrm{g} / \mathrm{mL})$, and brefeldin A (BFA) $(1 \mu \mathrm{g} / \mathrm{mL})$ for 6 hours. The percentages of IFN- $\gamma-$, TNF-, and IL-2-producing cells were analyzed by flow cytometry. (E) IFN- $\gamma$, TNF, and IL-2 concentrations in the lungs, spleens, and peripheral blood were determined by ELISA. (F) The bacterial burden in the lungs was determined by plate count and calculated as CFU per lung. (C) Lung sections were stained with $\mathrm{H} \& \mathrm{E}$ and analyzed by histopathology under the microscope. Scale bars: $50 \mu \mathrm{m}$. Data represent the mean \pm SD from at least 3 independent experiments. ${ }^{*} P<0.05,{ }^{* *} P<0.01$, and ${ }^{* * *} P<0.001$, by unpaired Student's $t$ test (B-F).

Moreover, we found that TREM-2 promoted STAT1 and STAT4 phosphorylation and enhanced T-bet expression and IFN- $\gamma$ production in $\mathrm{CD}^{+}{ }^{+} \mathrm{T}$ cells. TREM-2-promoted Th1 differentiation was suppressed by treatment with the ZAP70 inhibitor PP2. The stronger activity of ZAP70 and CD3 $\zeta$ was more often observed in Th1 than in Th2 differentiation (53). Selective blockage of ZAP70 considerably impaired $\mathrm{T}$ cell ability to proliferate and produce IFN- $\gamma$ upon TCR/CD3 stimulation (53). Meanwhile, IL-2R/STAT4 and IFNR/STAT1 signaling was indispensable for T-bet regulation and Th1 differentiation $(39,40)$. These results indicated that CD35/ZAP70/STATs signaling is crucial for TREM-2-enhanced Th1 cell responses. 

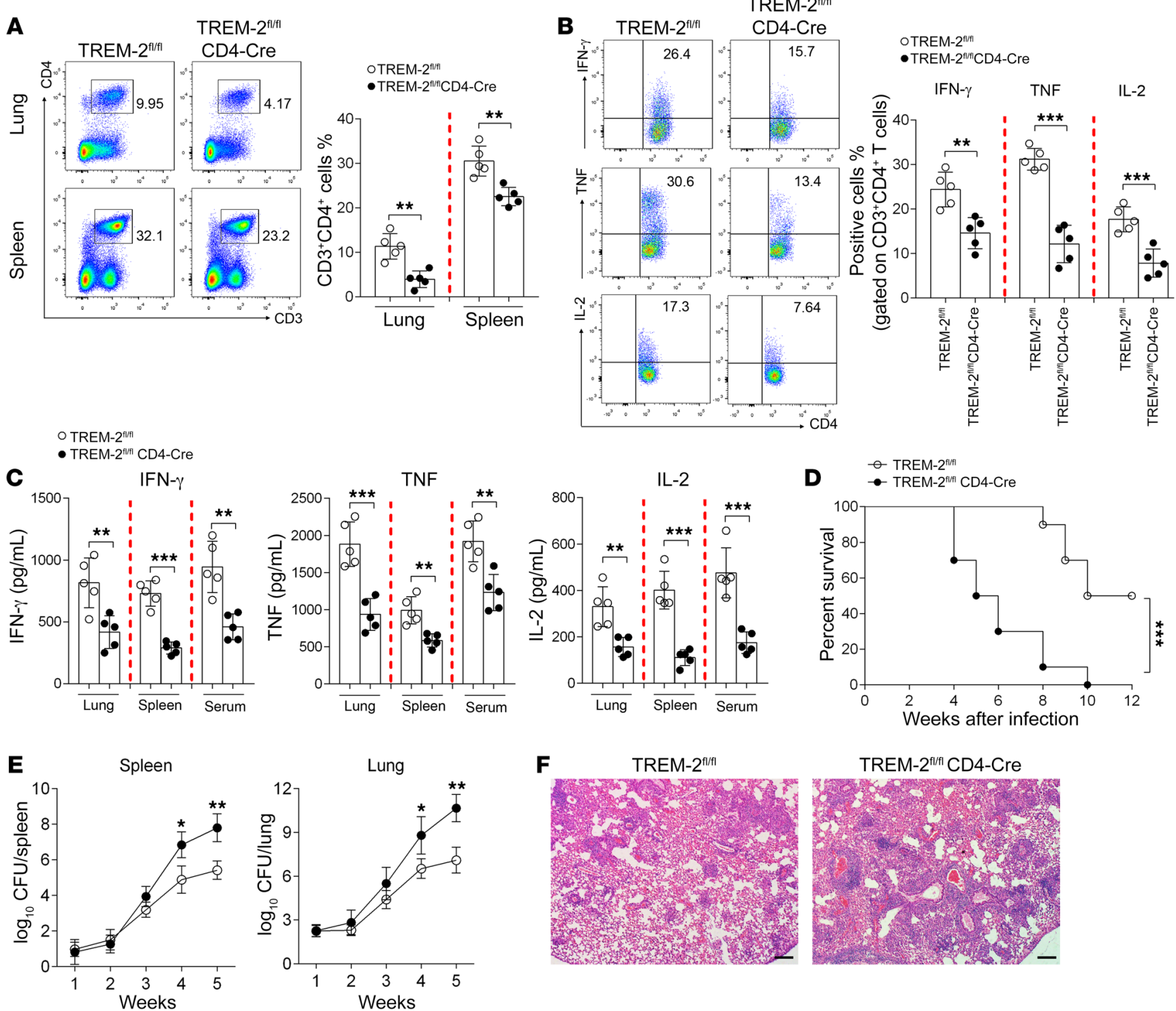

Figure 9. CD4-specific conditional KO of TREM-2 impairs proinflammatory Th1 responses against $M$. tuberculosis infection in vivo. TREM-2 fl/fl $^{f(n d}$ TREM-2 ${ }^{f / f f}$ CD4-Cre mice $(n=5)$ were infected i.v. with $1 \times 10^{6} \mathrm{CFU}$ H37Rv. On day $28 \mathrm{p}$.i., lungs and spleens were collected. (A) The frequency of pulmonary and splenic $\mathrm{CD}^{+} \mathrm{T}$ cells was determined by flow cytometry. (B) Splenocytes were stimulated with PMA (50 $\left.\mathrm{nM}\right)$, ionomycin $(1 \mu \mathrm{g} / \mathrm{mL})$, and BFA ( $\left.1 \mu \mathrm{g} / \mathrm{mL}\right)$ for 6 hours. The percentages of IFN- $\gamma-$, TNF-, and IL-2-producing cells were analyzed by flow cytometry. (C) IFN- $\gamma$, TNF, and IL-2 concentrations in the lungs, spleens, and peripheral blood were determined by ELISA. (D) Survival rates were determined for individual groups of mice 12 weeks after H37Rv infection. (E) Bacterial burden in the lungs was determined by plate count and calculated as CFU per lung. (F) Lung sections were stained with H\&E and histopathologically examined under the microscope. Scale bars: $50 \mu \mathrm{m}$. Data represent the mean \pm SD from at least 3 independent experiments. ${ }^{*} P<0.05$, ${ }^{* *} P<0.01$, and ${ }^{* *} P<0.001$, by unpaired Student's $t$ test $(\mathbf{A}-\mathbf{C}$ ) and 2-way ANOVA ( $\mathbf{D}$ and $\mathbf{E}$ ).

It has been reported that STAT1 (Ser727) phosphorylation was partially dependent on IFN- $\gamma(54)$. TCR stimulation also triggers STAT1 (Ser727) phosphorylation in the absence of IFN- $\gamma$ signaling $(55,56)$. Studies have reported that IFN- $\gamma \mathrm{R}$ is an integral part of TCR complex (41). Our study demonstrated that TREM-2 interacted with $\mathrm{CD} 3 \zeta$ and IFN- $\gamma \mathrm{R}$, but not IL-4R, in $\mathrm{CD} 4^{+} \mathrm{T}$ cells, suggesting that TREM-2 may be an integral part of the TCR-IFN- $\gamma$ R complex. To dissociate the effect of TCR versus IFN- $\gamma$ stimulus, we analyzed the phosphorylation of STAT1 and STAT4 in TREM-2+ $\mathrm{CD} 4^{+} \mathrm{T}$ cells stimulated with anti-CD3/anti-CD28 Abs in the presence of anti-IFN- $\gamma \mathrm{R}$-neutralizing Ab. Blockage of IFN- $\gamma$ sig- naling reduced the phosphorylation of STAT1 and STAT4, as well as T-bet expression in TREM-2 $2^{+} \mathrm{CD} 4^{+} \mathrm{T}$ cells, while had no effect on TREM-2-CD4+ $\mathrm{T}$ cells. These data indicated that the TREM-2induced Th1 response was dependent on TCR/IFN- $\gamma$ R signals.

Since Th1 response is critical for eliminating intracellular pathogens, we next examined the role of TREM-2-bearing CD $4^{+} \mathrm{T}$ cells in a murine model of M. tuberculosis infection. Results demonstrated that TREM-2 promoted a proinflammatory Th1 response to reduce the bacterial burden and granuloma formation after $M$. tuberculosis infection. This observation is consistent with other in vivo studies showing that TREM-2 deficiency attenuates the host 
inflammation during chronic infection/inflammation models (17, $21,22)$. The proinflammatory effects of TREM-2 in chronic infection/inflammation models appear to be contrast with the wellknown antiinflammatory property of TREM-2 in the innate immunity. Therefore, we hypothesize that TREM-2 may execute distinct functions on innate and adaptive immune cells, resulting in different outcomes during acute and chronic infections or inflammation.

To sum up, the present study explored the role of TREM- 2 on $\mathrm{CD} 4^{+} \mathrm{T}$ cells. We found that TREM- 2 expression on $\mathrm{CD} 4^{+} \mathrm{T}$ cells was induced by infection and inflammation. More important, TREM-2 interacted with the TCR-CD3ל-ZAP70 complex as well as the IFN- $\gamma \mathrm{R}$ in $\mathrm{CD}^{+} \mathrm{T}$ cells, subsequently activating STAT1/STAT4 signaling to enhance proinflammatory Th1 responses. These findings reveal an expanded function of TREM-2 and elucidate the TREM-2-mediated regulatory mechanism in adaptive immunity and host inflammation that may provide a promising therapeutic target for TB and other infectious and inflammatory diseases.

\section{Methods}

Human participants. Patients with active pulmonary TB $(n=116)$, latent TB $(n=30)$, cured TB $(n=43)$, COPD $(n=22)$, or sepsis $(n=22)$ were recruited from The Fifth Affiliated Hospital of Sun Yat-sen University (Zhuhai, China). All the patients were selected based on clinical diagnosis and laboratory information. Patients with TB were serologically confirmed as HIV negative. Patients with COPD were confirmed as T-SPOT negative. The exclusion criteria included patients with other pulmonary diseases (pneumonia, lung cancer, etc.), or under chemotherapy or anti-TB therapy. HCs $(n=81)$ were randomly recruited from individuals undergoing health checkup at The Fifth Affiliated Hospital of Sun Yat-sen University, and confirmed as T-SPOT negative. Clinical characteristics and laboratory results for the patients with TB and HCs are provided in Supplemental Table 1.

Generation of CD4 specific TREM-2-KO mice. Mice with loxPflanked alleles of TREM- 2 at exons 2 and $3\left(\right.$ TREM- $\left.2^{f / f f}\right)$ were generated at the Model Animal Research Center (MARC) of Nanjing University (Nanjing, China). Mice were backcrossed with mice on a C57BL/6J background for more than 6 generations. To generate mice with a CD4-specific KO of the TREM-2 allele, TREM-2 $2^{f / f l}$ mice were crossed with mice expressing Cre recombinase under the control of the CD4 promoter (CD4-Cre mice, The Jackson Laboratory, stock no. 022071) to achieve CD4-specific deletion of TREM-2 (TREM-2f/fll CD4-Cre) (Supplemental Figure 17). Six- to 8-week-old female mice (TREM-2 $2^{f / f l}$ vs. TREM-2 $\left.2^{f / f l} \mathrm{CD} 4-\mathrm{Cre}\right)$ were used in the experiments.

Generation of mixed BM chimeric mice. Six- to 8-week-old female Rag2 ${ }^{-1-}$ mice were irradiated with $9.5 \mathrm{~Gy}$ to eliminate the bone marrow-derived (BM-derived) cells, followed by the transfer of mixed BM cells from CD45.1 WT mice and CD45.2 TREM-2-- mice at a ratio of 1:1 via i.v. injection. Eight weeks later, the mice were infected i.v. with $1 \times 10^{6} \mathrm{CFU}$ H37Rv.

Reconstitution of $\mathrm{CD}^{+} \mathrm{T}$ cells in Rag2-- mice. Six- to 8-week-old female C57BL/6 mice were purchased from the Guangdong Medical Laboratory Animal Center. Rag2 ${ }^{--}$mice were purchased from Guangzhou Sebiona Biological Science and Technology Co. Ltd. TREM-2-1mice were provided by Marco Colonna (Washington University, St. Louis, Missouri, USA). Purified WT versus TREM-2- CD $4^{+} \mathrm{T}$ cells or TREM- $2^{-}$versus TREM- $2^{+}$cells $\left(5 \times 10^{6}\right.$ cells/mice $)$ were adoptively transferred into $\mathrm{Rag}^{-/-}$recipient mice by i.v. injection.
Bacterial culture. M. bovis BCG strain 19015 and M. tuberculosis H37Rv strain 25618 were purchased from the American Type Culture Collection (ATCC) and were grown in Middlebrook 7H9 broth medium or on $7 \mathrm{H} 10$ agar plates supplemented with $10 \%$ oleic albumin dextrose catalase (OADC) at $37^{\circ} \mathrm{C}$. M. bovis BCG or the $M$. tuberculosis strain $\mathrm{H} 37 \mathrm{Rv}$ was homogenized to generate a single-cell suspension for infection of cells as reported previously (23). Experiments using the virulent strain (H37Rv) were performed in the Biosafety Level-3 Laboratory (BSL-3) at Sun Yet-Sen University (Guangzhou, China), with the approval of the Biological Safety Committee Board of Sun Yet-Sen University.

M. tuberculosis infection. Rag $2^{-1-}$ mice reconstituted with TREM-2-1versus WT cells or with TREM-2+CD4 $4^{+}$versus TREM-2-CD4 ${ }^{+} \mathrm{T}$ cells were infected i.p. with $1 \times 10^{6} \mathrm{CFU}$ H37Rv. Mixed BM chimeric mice, $T R E M-2^{f / f l}$ mice, and TREM- $2^{f / f l} \mathrm{CD} 4-\mathrm{Cre}$ mice were infected i.v. with $1 \times 10^{6} \mathrm{CFU}$ H37Rv. On day 28 p.i., the bacterial load in the lungs and spleen of each mouse was determined by plate count with 7H10 agar. M. tuberculosis-infected mouse lungs were collected, fixed with $10 \%$ buffered formalin, and embedded with paraffin. Tissue sections (5 $\mu \mathrm{m})$ were stained with $\mathrm{H} \& \mathrm{E}$ and histopathologically examined under an Olympus microscope (Olympus).

Preparation of single scattered lung cells. Lung tissue was collected from euthanized mice and washed twice in PBS to remove the remaining blood. Lung tissues were cut with scissors and tweezers into small pieces and put into digestive solution containing $100 \mu \mathrm{g} / \mathrm{mL}$ collagenase D (MilliporeSigma) and $10 \mu \mathrm{g} / \mathrm{mL}$ DNase I (Thermo Fisher Scientific), followed by shaking for 1 hour at $37^{\circ} \mathrm{C}$. After the digestion, cells were collected through a $70 \mu \mathrm{m}$ cell filter and centrifuged at $600 \mathrm{~g}$ and used for further experiments.

Flow cytometry. The following fluorescent dye-labeled anti-human Abs were used: CD3 (clone UCHT1, BD Biosciences [BD]); CD4 (clone L200, BD); CD8 (clone RPA-T8, BD); CD45RA (clone HI100, BD); CD45RO (clone UCHL1, BD); CD27 (clone M-T271, BD); CD69 (clone FN50, eBioscience); CCR7 (clone 150503, BD); CXCR3 (clone G025H7, BioLegend); CD44 (clone G44-26, BD); CD25 (clone BC96, eBioscience); TREM-2 (clone 237920, R\&D Systems); TNF (clone MAb11, eBioscience); IFN- $\gamma$ (clone 4S.B3, eBioscience); IL-2 (clone MQ117H12, BioLegend); T-bet (clone O4-46, BD); p-ZAP70 (Tyr319) (clone

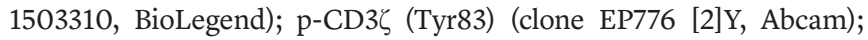
p-STAT1 (Tyr701) (clone A15158B, BioLegend); and p-STAT4 (Tyr693) (clone 38/p-STAT4, BD). The following fluorescent dye-labeled antimouse Abs were used: CD3 (clone 145-2C11, BD); CD4 (clone RM4-5, BD); CD8 (clone 53-6.7, BD); CD45.1 (clone A20, BD); CD45.2 (clone 104, BD); CD69 (clone H1.2F3, eBioscience); CD25 (clone PC61, eBioscience); CD44 (clone IM7, BD); CD62L (clone MEL-14, BD); TNF (clone MP6-XT22, eBioscience); IFN- $\gamma$ (clone XMG1.2, eBioscience); and T-bet (clone 4B10, BD). For intracellular molecule phosphorylation staining, cells were incubated with anti-CD3 $\mathrm{Ab}$ in the presence of IL-2 (10 $\mu \mathrm{g} / \mathrm{mL}, \mathrm{R} \& D$ Systems) or IFN- $\gamma(10 \mu \mathrm{g} / \mathrm{mL}, \mathrm{R} \& D$ Systems $)$ and then analyzed with the True-Phos Perm Buffer Kit (BioLegend) according to the manufacturer's instructions. Samples were detected using a BD FACSCaliber or BD LSR II cytometer and analyzed with FlowJo software (Tree Star). The gating strategies used to determine TREM-2 expression on cell populations in human PBMCs and mouse lung cells are shown in Supplemental Figures 18 and 19, respectively.

TREM-2-Fc staining. Recombinant human TREM-2-Fc fusion protein (hTREM-2-Fc) and mouse TREM-2-Fc were purchased from R\&D 
Systems. hTREM-2-Fc consists of the human TREM-2 (Met1-Ser174) extracellular domain with linker and human IgG1 (Pro100-Lys330). Murine TREM-2-Fc (mTREM-2-Fc) consists of mouse TREM-2 (Leu19-Pro168) and an extracellular domain with linker and human IgG1 (Pro100-Lys330). TREM-2 ligand staining was performed as previously described (5). Briefly, $0.5 \mu$ g TREM-2-Fc or human IgG1 (R\&D Systems) was precomplexed with $2.5 \mu \mathrm{g}$ PE-labeled anti-human IgG1 (Miltenyi Biotec) for 30 minutes. Cells $\left(2 \times 10^{5}\right)$ were stained for 1 hour on ice. Samples were analyzed on a BD FACSCaliber Cytometer.

Cell sorting and culturing. Human CD $14^{+}$monocytes, $\mathrm{CD} 4^{+} \mathrm{T}$ cells, and $\mathrm{CD}^{+} \mathrm{T}$ cells were isolated from PBMCs by positive selection using the magnetic cell-sorting system (BD). The purities of sorted cells (both $>95 \%$ ) were determined by flow cytometry (Supplemental Figure 20A). Mouse WT or TREM-2-- CD $4^{+} \mathrm{T}$ cells were sorted from mouse splenocytes using a magnetic cell-sorting system (BD), and the purity of isolated cells was confirmed (Supplemental Figure 20B). TREM- $2^{-} \mathrm{CD} 4^{+}$or TREM- $2^{+} \mathrm{CD} 4^{+} \mathrm{T}$ cells were respectively sorted from C57BL/6 mouse splenocytes or human PBMCs by flow cytometry using the BD FACSAria. Sorted TREM- $-2^{-} \mathrm{CD} 4^{+}$or TREM-2 ${ }^{+} \mathrm{CD} 4^{+} \mathrm{T}$ cells were verified as a group of $\mathrm{CD} 11 \mathrm{~b}^{-} \mathrm{CD} 11 \mathrm{c}^{-} \mathrm{CD} 19^{-} \mathrm{CD} 4^{+}$cells (Supplemental Figure 21). HEK293T cells (ATCC, GRL-11268 strain) and Jurkat cells (ATCC, TIB-152 strain) were cultured in DMEM or 1640 medium supplemented with $10 \%$ FBS and $100 \mathrm{U} / \mathrm{mL}$ penicillin and $100 \mu \mathrm{g} / \mathrm{mL}$ streptomycin and then incubated at $37^{\circ} \mathrm{C}$ in a humidified incubator with $5 \% \mathrm{CO}_{2}$.

$D C$ generation. Human monocyte-derived DCs were cultured as previously described (23). DCs were obtained from $\mathrm{CD} 14^{+}$monocytes after culturing with granulocyte-macrophage CSF (GM-CSF, $20 \mathrm{ng} / \mathrm{mL}$ ) and IL-4 (20 ng/mL) for 5 days. For mouse DCs, BM cells were cultured with $20 \mathrm{ng} / \mathrm{mL}$ GM-CSF and harvested for the stimulation assay on day 7.

TCR activation. For TCR stimulation, human TREM- $2^{+} \mathrm{CD} 4^{+}$versus TREM-2-CD4 ${ }^{+} \mathrm{T}$ cells were incubated for the indicated durations with heat-killed, H37Rv-primed DCs or anti-CD3 $(1 \mu \mathrm{g} / \mathrm{mL}$, clone OKT3, BD) and anti-CD28 (1 $\mu \mathrm{g} / \mathrm{mL}$, clone CD28.2, BD) Abs plus IL-2 $(10 \mathrm{ng} / \mathrm{mL})$ and IFN- $\gamma(10 \mathrm{ng} / \mathrm{mL})$ or IL-4 $(20 \mathrm{ng} / \mathrm{mL})$, whereas mouse TREM $-2^{+} \mathrm{CD} 4^{+}$versus TREM-2- or WT versus TREM-2-- ${ }^{-1} 4^{+}$ $\mathrm{T}$ cells were incubated with heat-killed, H37Rv-primed DCs or antiCD3 $(1 \mu \mathrm{g} / \mathrm{mL}$, clone 145-2C11, BioLegend) and anti-CD28 $(1 \mu \mathrm{g} / \mathrm{mL}$, clone 37.51, BioLegend) Abs $(1 \mu \mathrm{g} / \mathrm{mL})$ plus IL-2 and IFN- $\gamma(20 \mathrm{ng} /$ $\mathrm{mL})$. For IFN- $\gamma$ blocking, human TREM- $2^{+} \mathrm{CD} 4^{+}$versus TREM-2-CD $4^{+}$ $\mathrm{T}$ cells were incubated with anti-CD3/anti-CD28 Abs $(1 \mu \mathrm{g} / \mathrm{mL})$ plus anti-IFN- $\gamma \mathrm{Ab}(10 \mu \mathrm{g} / \mathrm{mL}$, clone B27, BD) or anti-IFN- $\gamma \mathrm{R} \mathrm{Ab}(10 \mu \mathrm{g} /$ $\mathrm{mL}$, clone ab280353, Abcam). For antigen stimulation, PBMCs were incubated with ESAT- 6 and CFP-10 $(10 \mu \mathrm{g} / \mathrm{mL}$, Shanghai Gene-Optimal Science \& Technology Co., Ltd.) overnight. To study the effect of PP2 or SH-4-54 on the T cell response, primary human or mouse CD $4^{+}$ T cells were pretreated with PP2 (250 nM, Selleck) or SH-4-54 (100 $\mathrm{nM}$, Selleck) or DMSO for 1 hour, and then stimulated with anti-CD3/ anti-CD28 Abs $(1 \mu \mathrm{g} / \mathrm{mL})$ for the indicated durations. The recombinant human or mouse cytokines, including GM-CSF, IL-4, IFN- $\gamma$, IL-2, were purchase from $R \& D$ Systems.

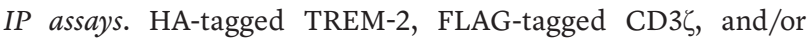
Myc-tagged ZAP70 plasmids were generated by molecular cloning. The HA tag, FLAG tag, and Myc tag were placed on the C-terminal of TREM-2, CD3 $\zeta$, and ZAP70. The indicated constructs were transfected into HEK293T cells using polyethylenimine for 24 hours, and cell lysates were immunoprecipitated with anti-FLAG beads and then assessed by Western blotting. Protein from cell lysates was respectively immunoprecipitated with anti-human TREM-2 Ab (clone D8I4C, Cell Signaling Technology [CST]), anti-mouse TREM-2 Ab (clone EPR20243, Abcam), and anti-CD3 Ab (clone H146-968) versus isotype-matched IgG, followed by Western blotting for TREM-2, $\mathrm{CD} 3 \zeta, \mathrm{DAP} 12, \mathrm{IFN} \gamma \mathrm{R}$, and TCR $\alpha / \beta$.

$T$ cell proliferation assays. TREM-2+ versus TREM-2- or WT versus TREM-2-/- $\mathrm{CD}^{+}$T cells isolated from human PBMCs or mouse splenocytes were labeled with CFSE ( $5 \mu \mathrm{M}$, Invitrogen, Thermo Fisher Scientific) and then seeded in 96-well plates $\left(1 \times 10^{5}\right.$ cells/well $)$ with or without simulation with heat-killed, H37Rv-primed DCs, TREM-2-Fc, or human IgG $(20 \mu \mathrm{g} / \mathrm{mL})$, anti-CD3 $(1 \mu \mathrm{g} / \mathrm{mL})$, anti-CD28 $(1 \mu \mathrm{g} / \mathrm{mL})$, and IL-2 (10 ng/mL). CFSE dilution was analyzed by flow cytometry on day 3. The gating strategy for the CFSE proliferation array is shown in Supplemental Figure 22.

Immunofluorescence microscopy. PBMCs were centrifuged at $600 \mathrm{~g}$ for 5 minutes and then fixed with 1\% paraformaldehyde (MilliporeSigma) for 15 minutes. Cells were stained with FITC-labeled anti-CD4 or anti-CD14 and PE-labeled anti-TREM-2 Abs for 15 minutes and then visualized under a fluorescence microscope (Olympus).

ELISAs. Lungs and spleens were collected from M. tuberculosisinfected mice on day 28 p.i. and then homogenized in $2 \mathrm{~mL}$ PBS containing $0.05 \%$ Tween- 80 . Homogenized tissue supernatants were filtered with a $0.22 \mu \mathrm{m}$ membrane and analyzed using an ELISA kit (R\&D systems) for mouse IFN- $\gamma$, TNF, and IL-2, according to the manufacturer's guidelines.

Western blot analysis. Cells were lysed with loading buffer containing $2 \%$ SDS and then boiled at $100^{\circ} \mathrm{C}$ for 15 minutes. Proteins were separated by SDS-PAGE and transferred onto PVDF membranes. Membranes were blocked with TBS containing 5\% milk and $0.1 \%$ Tween-20, followed by incubation with anti-p-ZAP70 (Tyr319) (clone 65E4, CST); anti-p-CD3ל (Tyr83) (clone EP776(2)Y, Abcam); antip-STAT1 (Ser727) (clone 58D6, CST); anti-p-STAT4 (Tyr693) (clone D2E4, CST); anti-IFN $\gamma$ R1 (clone epr7866, Abcam); or anti-TCR $\alpha / \beta$ (clone R73, Abcam). Then, the membranes were incubated with the appropriate secondary $\mathrm{Ab}$ at room temperature (RT) for 1 hour, followed by visualization with an ECL kit (KeyGEN) according to the manufacturer's instructions.

Statistics. Data analyses were performed using GraphPad Prism 8.0 (GraphPad Software). Differences between the means of 2 groups were analyzed using an unpaired, 2-tailed Student's $t$ test. Multiple groups were analyzed using a 1-way ANOVA with Tukey's or Dunnett's post test. Data are shown as the mean \pm SD unless otherwise indicated. A P value of less than 0.05 was considered statistically significant.

Study approval. This study and all experimental protocols were approved by the ethics committees for human and animal experiments at the Zhongshan School of Medicine (Guangzhou, China) and The Fifth Affiliated Hospital of Sun Yat-Sen University (Zhuhai, China). For experiments involving human samples, written informed consent was obtained from all participants. The procedure was performed in accordance with the National Commission for the Protection of Subjects of Biomedical and Behavioral Research for animal experiments. All efforts were made to minimize suffering of the animals.

\section{Author contributions}

YW, MW, SM, XZ, SH, XL, HY, CC, J Liu, and J Li conducted the experiments. SM, XZ, and SH acquired data. ZW, JZ, LL, SG, and DH pro- 
vided scientific expertise and reagents. YW, MW, and XH designed studies, analyzed data, and wrote the manuscript. All authors read the final version of the manuscript and approved the submission.

\section{Acknowledgments}

This work was supported by grants from the National Natural Science Foundation of China (82072062, 31470877, 31670880, and 81801571); the National Science and Technology Key Projects for Major Infectious Diseases (2017ZX10302301-002); the Guangzhou Science and Technology Planning Project (201704020226 and 201604020006); the Guangdong Natural Science Foundation (2015A030311009); the National Key Research and Development Program of China (2016YFC1200105); the Guang- dong Natural Science Fund for Distinguished Young Scholars (2016A030306004); the Guangzhou Pearl River New Star Program (201610010064); the Development Project of Foshan Fourth People's Hospital (FSSYKF-2020003 and FSSYKF-2020017); and the Support Scheme of Guangzhou for Leading Talents in Innovation and Entrepreneurship (2017004). We thank Marco Colonna for providing TREM-2-/- mice and Haibo Zhou (Qingyuan People's Hospital, China) for helpful suggestions.

Address correspondence to: Xi Huang, Center for Infection and Immunity, the Fifth Affiliated Hospital of Sun Yat-sen University, Zhuhai 519000, China. Phone: 86.13694296389; Email: huangxi6@mail.sysu.edu.cn.
1. Reynolds JM, Dong C. Toll-like receptor regulation of effector T lymphocyte function. Trends Immunol. 2013;34(10):511-519.

2. Klesney-Tait J, et al. The TREM receptor family and signal integration. Nat Immunol. 2006;7(12):1266-1273

3. Ford JW, McVicar DW. TREM and TREM-like receptors in inflammation and disease. Curr Opin Immunol. 2009;21(1):38-46.

4. Bouchon A, et al. TREM-1 amplifies inflammation and is a crucial mediator of septic shock. Nature. 2001;410(6832):1103-1107.

5. Hamerman JA, et al. Cutting edge: inhibition of TLR and FcR responses in macrophages by triggering receptor expressed on myeloid cells (TREM)-2 and DAP12. J Immunol. 2006;177(4):2051-2055.

6. Perugorria MJ, et al. Non-parenchymal TREM-2 protects the liver from immune-mediated hepatocellular damage. Gut. 2019;68(3):533-546.

7. Wu M, et al. TREM-1 amplifies corneal inflammation after Pseudomonas aeruginosa infection by modulating Toll-like receptor signaling and Th1/Th2-type immune responses. Infect Immun. 2011;79(7):2709-2716.

8. Turnbull IR, et al. Cutting edge: TREM-2 attenuates macrophage activation. JImmunol. 2006;177(6):3520-3524.

9. Hsieh CL, et al. A role for TREM2 ligands in the phagocytosis of apoptotic neuronal cells by microglia. J Neurochem. 2009;109(4):1144-1156.

10. Wang Y, et al. TREM2 lipid sensing sustains the microglial response in an Alzheimer's disease model. Cell. 2015;160(6):1061-1071.

11. Ulrich JD, et al. Elucidating the role of TREM 2 in Alzheimer's disease. Neuron. 2017;94(2):237-248.

12. Schlepckow K, et al. An Alzheimer-associated TREM2 variant occurs at the ADAM cleavage site and affects shedding and phagocytic function. EMBO Mol Med. 2017;9(10):1356-1365.

13. Ulland TK, et al. TREM2 maintains microglial metabolic fitness in Alzheimer's disease. Cell. 2017;170(4):649-663.

14. Kleinberger G, et al. TREM2 mutations implicated in neurodegeneration impair cell surface transport and phagocytosis. Sci Transl Med. 2014;6(243):ra286.

15. Stefano L, et al. The surface-exposed chaperone, Hsp60, is an agonist of the microglial TREM2 receptor. JNeurochem. 2009;110(1):284-294.
16. Poliani PL, et al. TREM2 sustains microglial expansion during aging and response to demyelination. JClin Invest. 2015;125(5):2161-2170.

17. Kawabori M, et al. Triggering receptor expressed on myeloid cells 2 (TREM2) deficiency attenuates phagocytic activities of microglia and exacerbates ischemic damage in experimental stroke. J Neurosci. 2015;35(8):3384-3396.

18. Atagi $Y$, et al. Apolipoprotein $E$ is a ligand for triggering receptor expressed on myeloid cells 2 (TREM2). JBiol Chem. 2015;290(43):26043-26050.

19. Boza-Serrano A, et al. Galectin-3, a novel endogenous TREM2 ligand, detrimentally regulates inflammatory response in Alzheimer's disease. Acta Neuropathol. 2019;138(2):251-273.

20. Gawish R, et al. Triggering receptor expressed on myeloid cells-2 fine-tunes inflammatory responses in murine Gram-negative sepsis. FASEB J. 2015;29(4):1247-1257.

21. Weehuizen TA, et al. Triggering receptor expressed on myeloid cells (TREM)-2 impairs host defense in experimental melioidosis. PLoS Negl Trop Dis. 2016;10(6):e0004747.

22. Leyns CEG, et al. TREM2 deficiency attenuates neuroinflammation and protects against neurodegeneration in a mouse model of tauopathy. Proc Natl Acad Sci U S A. 2017;114(43):11524-11529.

23. Wu Y, et al. Activation and regulation of blood V $\delta 2 \mathrm{~T}$ cells are amplified by TREM-1 $1^{+}$during active pulmonary tuberculosis. JImmunol. 2018;200(5):1627-1638.

24. King RG, et al. Trem-like transcript 2 is expressed on cells of the myeloid/granuloid and B lymphoid lineage and is up-regulated in response to inflammation. J Immunol. 2006;176(10):6012-6021.

25. Hashiguchi $\mathrm{M}$, et al. Triggering receptor expressed on myeloid cell-like transcript 2 (TLT2) is a counter-receptor for B7-H3 and enhances T cell responses. Proc Natl Acad Sci U S A. 2008;105(30):10495-10500.

26. Hoogendijk AJ, et al. Soluble and cell-associated triggering receptor expressed on myeloid cells-1 and -2 in patients with pulmonary tuberculosis. Jinfect. 2015;71(6):706-709.

27. DuPage M, Bluestone JA. Harnessing the plasticity of CD4(+) T cells to treat immune-mediated disease. Nat Rev Immunol. 2016;16(3):149-163.

28. Lewinsohn DA, et al. Polyfunctional $\mathrm{CD} 4^{+} \mathrm{T}$ cells as targets for tuberculosis vaccination. Front Immunol. 2017;8:1262.
29. Salgame P. Host innate and Th1 responses and the bacterial factors that control Mycobacterium tuberculosis infection. Curr Opin Immunol. 2005;17(4):374-380.

30. Sieling PA, et al. IL-12 regulates T helper type 1 cytokine responses in human infectious disease. Jimmunol. 1994;153(8):3639-3647.

31. Haring JS, et al. In vivo generation of pathogen-specific Th1 cells in the absence of the IFN-gamma receptor. JImmunol. 2005;175(5):3117-3122.

32. Feng CG, et al. NK cell-derived IFN-gamma differentially regulates innate resistance and neutrophil response in $\mathrm{T}$ cell-deficient hosts infected with Mycobacterium tuberculosis. J Immunol. 2006;177(10):7086-7093.

33. Allie N, et al. Prominent role for T cell-derived tumour necrosis factor for sustained control of Mycobacterium tuberculosis infection. Sci Rep. 2013;3:1809.

34. Hazlett LD. Role of innate and adaptive immunity in the pathogenesis of keratitis. Ocul Immunol Inflamm. 2005;13(2-3):133-138.

35. Prajeeth CK, et al. Effectors of Th1 and Th17 cells act on astrocytes and augment their neuroinflammatory properties. J Neuroinflammation. 2017;14(1):204

36. Rosenberg RN, et al. Genomics of Alzheimer disease: a review. JAMA Neurol. 2016;73(7):867-874.

37. Powell N, et al. Transcriptional regulation of the mucosal immune system mediated by T-bet. Mucosal Immunol. 2010;3(6):567-577.

38. Chen J, Liu X. The role of interferon gamma in regulation of $\mathrm{CD} 4+\mathrm{T}$-cells and its clinical implications. Cell Immunol. 2009;254(2):85-90.

39. Persky ME, et al. IL-12, but not IFN-alpha, promotes STAT4 activation and Th1 development in murine $\mathrm{CD} 4^{+} \mathrm{T}$ cells expressing a chimeric murine/human Stat2 gene. JImmunol. 2005;174(1):294-301.

40. Afkarian M, et al. T-bet is a STAT1-induced regulator of IL-12R expression in naïve CD4+ T cells. Nat Immunol. 2002;3(6):549-557.

41. Maldonado RA, et al. Control of T helper cell differentiation through cytokine receptor inclusion in the immunological synapse. J Exp Med. 2009;206(4):877-892.

42. Sakai S, et al. Defining features of protective CD4 T cell responses to Mycobacterium tuberculosis. Curr Opin Immunol. 2014;29:137-142. 
43. Goldberg MF, et al. Salmonella persist in activated macrophages in T cell-sparse granulomas but are contained by surrounding CXCR3 ligand-positioned Th1 cells. Immunity. 2018;49(6):1090-1102.

44. Wang X, et al. Association of mycobacterial antigen-specific $\mathrm{CD} 4(+)$ memory $\mathrm{T}$ cell subsets with outcome of pulmonary tuberculosis. J Infect. 2010;60(2):133-139.

45. Marin ND, et al. Reduced frequency of memory $\mathrm{T}$ cells and increased Th17 responses in patients with active tuberculosis. Clin Vaccine Immunol. 2012;19(10):1667-1676.

46. Pages F, et al. Effector memory T cells, early metastasis, and survival in colorectal cancer. N Engl JMed. 2005;353(25):2654-2666.

47. Ferrando-Martinez S, et al. CD27 and CCR7 expression on naive T cells, are both necessary?
Immunol Lett. 2010;127(2):157-158.

48. Chen X, et al. Engagement of Toll-like receptor 2 on CD 4(+) T cells facilitates local immune responses in patients with tuberculous pleurisy. JInfect Dis. 2009;200(3):399-408.

49. van Oers NS, et al. The 21- and 23-kD forms of TCR zeta are generated by specific ITAM phosphorylations. Nat Immunol. 2000;1(4):322-328.

50. Klammt $C$, et al. $T$ cell receptor dwell times control the kinase activity of Zap70. Nat Immunol. 2015;16(9):961-969.

51. Zhou SL, et al. TREM2 variants and neurodegenerative diseases: a systematic review and meta-analysis. JAlzheimers Dis. 2019;68(3):1171-1184.

52. Andreone BJ, et al. Alzheimer's-associated PLC $\gamma 2$ is a signaling node required for both TREM2 function and the inflammatory response in human microglia. Nat Neurosci. 2020;23(8):927-938.

53. Au-Yeung BB, et al. A genetically selective inhibitor demonstrates a function for the kinase Zap70 in regulatory $\mathrm{T}$ cells independent of its catalytic activity. Nat Immunol. 2010;11(12):1085-1092.

54. Lee CK, et al. STAT1 affects lymphocyte survival and proliferation partially independent of its role downstream of IFN-gamma. J Immunol. 2000;164(3):1286-1292.

55. Lafont V, et al. Antigen receptor signal transduction: activating and inhibitory antigen receptors regulate STAT1 serine phosphorylation. Eur J Immunol. 2000;30(7):1851-1860.

56. Gamero AM, Larner AC. Signaling via the $\mathrm{T}$ cell antigen receptor induces phosphorylation of Stat1 on serine 727. J Biol Chem. 2000;275(22):16574-16578. 